NISTIR 8043

\title{
Determination of the compliance of NIST Charpy Impact Machines
}

Enrico Lucon

This publication is available free of charge from:

http://dx.doi.org/10.6028/NIST.IR.8043 
NISTIR 8043

\title{
Determination of the compliance of NIST Charpy Impact Machines
}

\author{
Enrico Lucon \\ Applied Chemicals and Materials Division \\ Material Measurement Laboratory
}

This publication is available free of charge from:

http://dx.doi.org/10.6028/NIST.IR.8043

February 2015

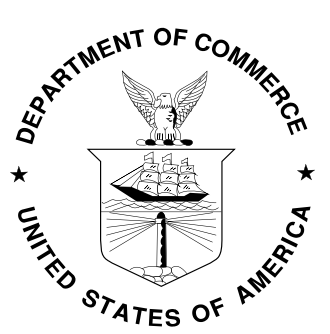

U.S. Department of Commerce

Penny Pritzker, Secretary

National Institute of Standards and Technology Willie May, Acting Under Secretary of Commerce for Standards and Technology and Acting Director 
Certain commercial entities, equipment, or materials may be identified in this document in order to describe an experimental procedure or concept adequately. Such identification is not intended to imply recommendation or endorsement by the National Institute of Standards and Technology, nor is it intended to imply that the entities, materials, or equipment are necessarily the best available for the purpose.

National Institute of Standards and Technology Internal Report 8043 Natl. Inst. Stand. Technol. Int. Report 8043, 22 pages (February 2015) CODEN: NTNOEF

This publication is available free of charge from: http://dx.doi.org/10.6028/NIST.IR.8043 


\begin{abstract}
The compliance of a Charpy impact machine, $C_{M}$, can be measured by means of a low-blow elastic test on an unnotched Charpy-type specimen, provided an instrumented striker is used. The resulting force/time and force/displacement test records can be analyzed according to three methods originally suggested by D. R. Ireland in 1973, each one resulting in an independent value of machine compliance. The three values are expected to be in agreement with each other within $10 \%$.

In this investigation, we measured the compliance of all NIST Charpy machines equipped with instrumented strikers, ranging from large-scale machines for testing full-size specimens to small-scale machines for testing miniaturized specimens. On each machine, three elastic low-blow tests were performed.

In most cases, good repeatability and consistency was observed among different tests and different analytical approaches. Machine compliance was found not to depend on machine capacity or hammer weight, but only on the design of the machine itself and the type of hammer (C-type, U-type, etc.).

Machine compliance, measured from an elastic low-blow test, can also be used for dynamically calibrating an instrumented striker, as an alternative to the conventional static calibration prescribed by test standards. For the NIST machines, dynamic conversion factors between applied force and striker output are systematically lower that static conversion factors, although the difference is generally small (less than $5 \%$ ).
\end{abstract}

\title{
Keywords
}

Dynamic striker calibration; instrumented Charpy striker; low-blow impact test; machine compliance; static striker calibration; unnotched Charpy specimen. 


\section{Table of Contents}

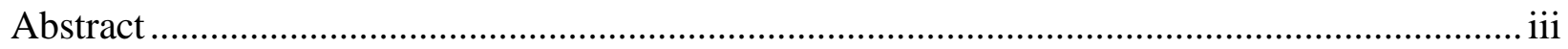

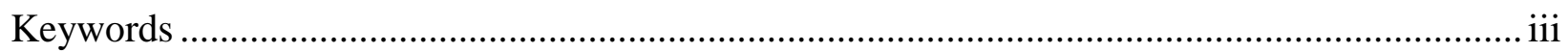

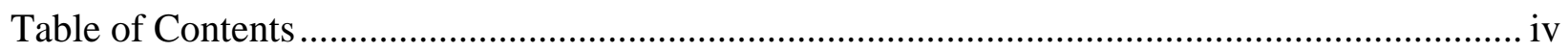

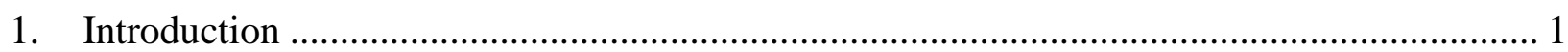

2. Measurement of the compliance of a Charpy impact machine ........................................ 3

3. Compliance measurements for the NIST Charpy machines........................................... 6

3.1 TO2 machine (instrumented striker: JS1) f..................................................... 8

3.2 TO3 machine (instrumented striker: JS1) ........................................................... 9

3.3 MPM-700 machine (instrumented striker: JS-1M) .............................................. 10

3.4 T-K machine (instrumented striker: MPM-S-79)............................................... 11

3.5 Table-Top machine (instrumented striker: KLST) ........................................... 11

3.6 Table-Top machine (instrumented striker: RHS) ............................................. 12

4. Summary of compliance values for the NIST Charpy machines .................................... 14

5. Use of machine compliance for the dynamic calibration of Charpy instrumented strikers .. 15

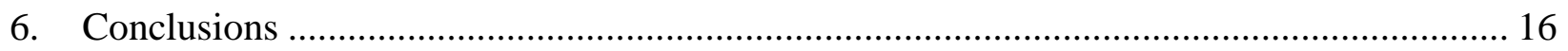

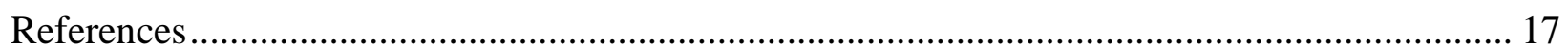




\section{Introduction}

Although the earliest known paper dealing with force measurements during an impact test [1] appeared one year earlier than the first pendulum machine publication [2], instrumented impact testing is often considered to be a relatively recent technical development of Charpy testing. In reality, it started to gain popularity in the technical community in the early 20 's, when it was considered a sort of laboratory curiosity [3]. However, it was in the 50's and 60's that the scientific community recognized that a more accurate understanding of the dynamic fracture process could be achieved only by instrumenting the pendulum machine, and more specifically by applying strain-gages to the striker in order to determine force/time and force/deflection records.

Nowadays, instrumented impact tests on Charpy V-notch specimens are standardized in international test standards such as ISO 14556 [4] and ASTM E2298 [5]. According to these standards, the analysis of an instrumented Charpy test consists of the determination of characteristic time, force, displacement, and absorbed energy values corresponding to the following events (Figure 1):

- general yield, or yielding across the entire specimen ligament;

- maximum force;

- initiation of brittle (unstable) fracture;

- arrest of brittle (unstable) fracture, or crack arrest;

- test termination.

Fully brittle specimens (lower shelf behavior) do not exhibit general yield, and typically maximum force coincides with the initiation of unstable fracture. Furthermore, the force at crack arrest is normally equal to zero. Fully ductile specimens (upper shelf behavior), on the other hand, do not exhibit unstable fracture.

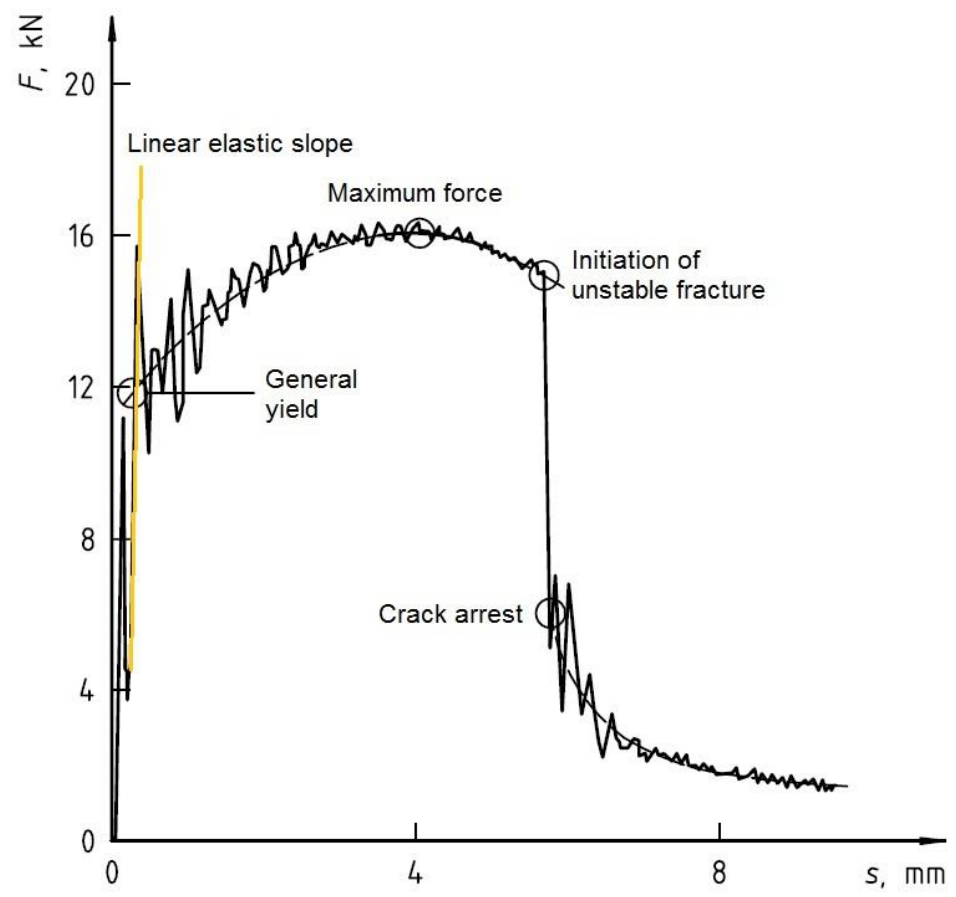

Figure 1 - Example of instrumented Charpy test record for a specimen tested in ductile-to-brittle transition regime. 
More recently, dynamic toughness measurements on fatigue precracked Charpy specimens were standardized as a mandatory annex (Annex A17) of the ASTM E1820 standard for the Measurement of Fracture Toughness [6]. In accordance with this procedure, instrumented impact tests of the type shown in Figure 1 are analyzed to determine values of stress intensity factor $(K)$ at impact loading rates. A similar standard is currently being developed by an ISO subcommittee, and should be soon officially published.

Although the elastic slope of the force/displacement test record is not explicitly mentioned by either ISO 14556 or ASTM 2298 as one of the test parameters to be reported, it is nevertheless a quantity which needs to be determined in order to establish the point corresponding to general yield: according to ASTM E2298 (\$11.4.1), "The force $F_{\text {gy }}$ is defined as the force at the intersection of the linear elastic part of the force-displacement curve, discarding inertia peak(s), and the fitted curve through the oscillations of the force-displacement curve following the onset of general yielding of the uncracked ligament."

In the initial elastic portion of an instrumented Charpy test, several force oscillations are observed, depending on the impact velocity and on the frequency response of the acquisition system. The first oscillation always corresponds to the inertia peak, which is caused by the temporary loss of contact between striker and specimen, induced by the acceleration of the specimen from rest [7]. In some instances, only one additional force oscillation (peak) is observed before the onset of general yielding, and the rising part of the second peak can be used for the establishment of the elastic slope of the test record, as in the example of Figure 1 (yellow line). This is the circumstance addressed by ISO 14556:2000, which refers to "the steeply rising part of second peak of the force-displacement curve" (clause 9.3).

However, in most cases instrumented test records exhibit more than one force oscillation before general yield, as in the actual instrumented test shown in Figure 2. Hence, the determination of the elastic slope in this case will significantly depend on the selection of which peaks belong to the elastic portion, and this selection is, unfortunately, dependent on the analyst's subjective opinion.

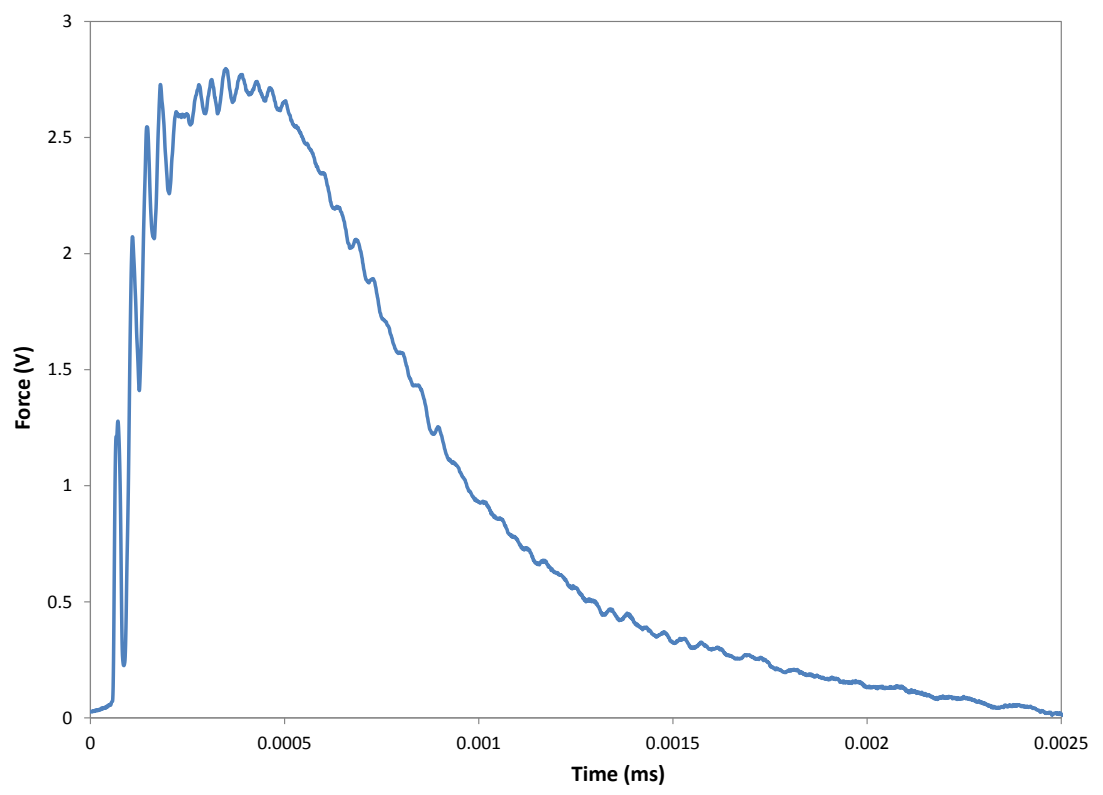

Figure 2 - Forceltime record for an actual instrumented Charpy test showing multiple force oscillations in the elastic portion. 
A more accurate, reproducible, and less subjective determination of the elastic slope of an instrumented Charpy test record is a key factor to decrease the uncertainty in the determination of the force at general yield $\left(F_{\text {gy }}\right)$, which is needed in several important applications such as the evaluation of dynamic yield strength [8] and the estimation of shear fracture appearance [9].

The elastic slope of an instrumented Charpy force/displacement curve contains two separate contributions, and can be expressed either in terms of overall (system) compliance, in units of $\mathrm{mm} / \mathrm{kN}$, or overall (system) stiffness, in units of $\mathrm{kN} / \mathrm{mm}$. We will use compliance in this investigation. The two components of experimental compliance, $C_{\text {exp }}$, are:

- $\quad$ specimen compliance, $C_{\mathrm{S}}$; and

- machine compliance, $C_{\mathrm{M}}$.

For a Charpy-V notch specimen, $C_{\mathrm{S}}$ in $\mathrm{mm} / \mathrm{kN}$ can be calculated from:

$$
C_{S}=\frac{1000}{E B}\left(\frac{S}{W-a}\right)^{2} f\left(\frac{a}{W}\right)
$$

where: $E$ is the material's elastic modulus at the test temperature (in $\mathrm{MPa}$ );

$B$ is the specimen thickness (in $\mathrm{mm}$ );

$S$ is the span, or distance between the machine anvils (in $\mathrm{mm}$ );

$W$ is the specimen width (in $\mathrm{mm}$ );

$a$ is the notch depth (in mm); and

$$
f\left(\frac{a}{W}\right)=1.193-1.98 \frac{a}{W}+4.478\left(\frac{a}{W}\right)^{2}-4.443\left(\frac{a}{W}\right)^{3}+1.739\left(\frac{a}{W}\right)^{4} \quad .
$$

For a typical Charpy specimen of steel with nominal dimensions ( $B=W=10 \mathrm{~mm}, a=2$ $\mathrm{mm})$, tested at room temperature $(E=207,000 \mathrm{MPa})$ on a machine with $S=40 \mathrm{~mm}$, the compliance yielded by Eq. 1 is $C_{\mathrm{S}}=0.011393 \mathrm{~mm} / \mathrm{kN}$, which corresponds to a specimen stiffness of $87.8 \mathrm{kN} / \mathrm{mm}$.

The compliance of a Charpy pendulum machine can be determined by means of an instrumented low-blow test ${ }^{1}$ on an unnotched Charpy specimen, according to a fundamental paper published by D. R. Ireland in 1974 [10]. The measurement of the compliance of several Charpy machines located in the NIST Charpy lab in Boulder, Colorado is the subject of this Internal Report.

\section{Measurement of the compliance of a Charpy impact machine}

As suggested by Ireland [10], the instrumented low-blow test on an unnotched Charpy specimen is the recommended procedure to measure machine compliance. Note that a low-blow test can also be performed on a notched specimen, however the presence of the notch introduces additional uncertainty and potential for experimental scatter, and therefore we decided to use exclusively unnotched specimens.

In a low-blow test, the pendulum hammer is dropped from a height such that the maximum available (potential) energy, $W_{0}$, is less than that required to produce any permanent

\footnotetext{
${ }^{1}$ In this report, by "low-blow test" we mean an impact test wherein the pendulum is dropped from a small angle, so that no plastic deformation of the specimen is produced.
} 
damage in the specimen, including any indentation-type deformation at the specimen load points. The specimen compliance of the unnotched specimen has to be accurately known from elastic beam theory, accounting for all possible contributions (tension, compression, and shear).

For an unnotched specimen (bar with square or rectangular cross section), the compliance $C_{\mathrm{S}(\mathrm{u})}$ is given by:

$$
C_{S(u)}=\frac{S^{3}}{48 E I}
$$

where $I$, the area moment of inertia, is expressed as:

$$
I=\frac{B W^{3}}{12}
$$

Table 1 provides the values of $C_{\mathrm{S}(\mathrm{u})}$ for several unnotched specimen types (full-size, sub-size and miniaturized), calculated by assuming nominal specimen dimensions. For the unnotched specimens actually used in this investigation, $C_{\mathrm{S}(\mathrm{u})}$ values were recalculated after measuring the actual dimensions.

Table 1 - Values of specimen compliance for various unnotched specimen configurations, based on nominal dimensions. NOTE: $C V N=$ Charpy V-Notch; SS = Sub-Size; KLST = KLeinSTprobe; RHS = Reduced Half-Size.

\begin{tabular}{|c|c|c|c|c|c|}
\hline $\begin{array}{c}\text { Specimen } \\
\text { type }\end{array}$ & $\begin{array}{c}B \\
(\mathrm{~mm})\end{array}$ & $\begin{array}{c}W \\
(\mathrm{~mm})\end{array}$ & $\begin{array}{c}I \\
\left(\mathrm{~mm}^{4}\right)\end{array}$ & $\begin{array}{c}S \\
(\mathrm{~mm})\end{array}$ & $\begin{array}{c}\boldsymbol{C}_{\text {s(u) }} \\
(\mathbf{m m} / \mathbf{k N})\end{array}$ \\
\hline $\mathrm{CVN}$ & 10 & 10 & 833.3 & 40 & $\mathbf{0 . 0 0 7 7}$ \\
$3 / 4 \mathrm{SS}$ & 7.5 & 10 & 625 & 40 & $\mathbf{0 . 0 1 0 3}$ \\
$2 / 3 \mathrm{SS}$ & 6.67 & 10 & 555.8 & 40 & $\mathbf{0 . 0 1 1 6}$ \\
$1 / 2 \mathrm{SS}$ & 5 & 10 & 416.7 & 40 & $\mathbf{0 . 0 1 5 5}$ \\
$1 / 4 \mathrm{SS}$ & 2.5 & 10 & 208.3 & 40 & $\mathbf{0 . 0 3 0 9}$ \\
KLST & 3 & 4 & 16 & 22 & $\mathbf{0 . 0 6 7 0}$ \\
RHS & 4.83 & 4.83 & 45.4 & 19.32 & $\mathbf{0 . 0 1 6 0}$ \\
\hline
\end{tabular}

A typical instrumented force/time record for a low-blow test on an unnotched $10 \times 10$ $\mathrm{mm}^{2}$ specimen is shown in Figure 3. There are three methods for determining machine compliance, $C_{\mathrm{M}}$, from this record.

Method 1 [11]

Determine the initial linear slope of the curve $\left(C_{\exp }^{-1}\right)$ and subtract the theoretical slope for the unnotched specimen $\left(C_{S(u)}^{-1}\right)$, to find the machine compliance by:

$$
C_{M}=C_{\exp }-C_{S(u)}
$$




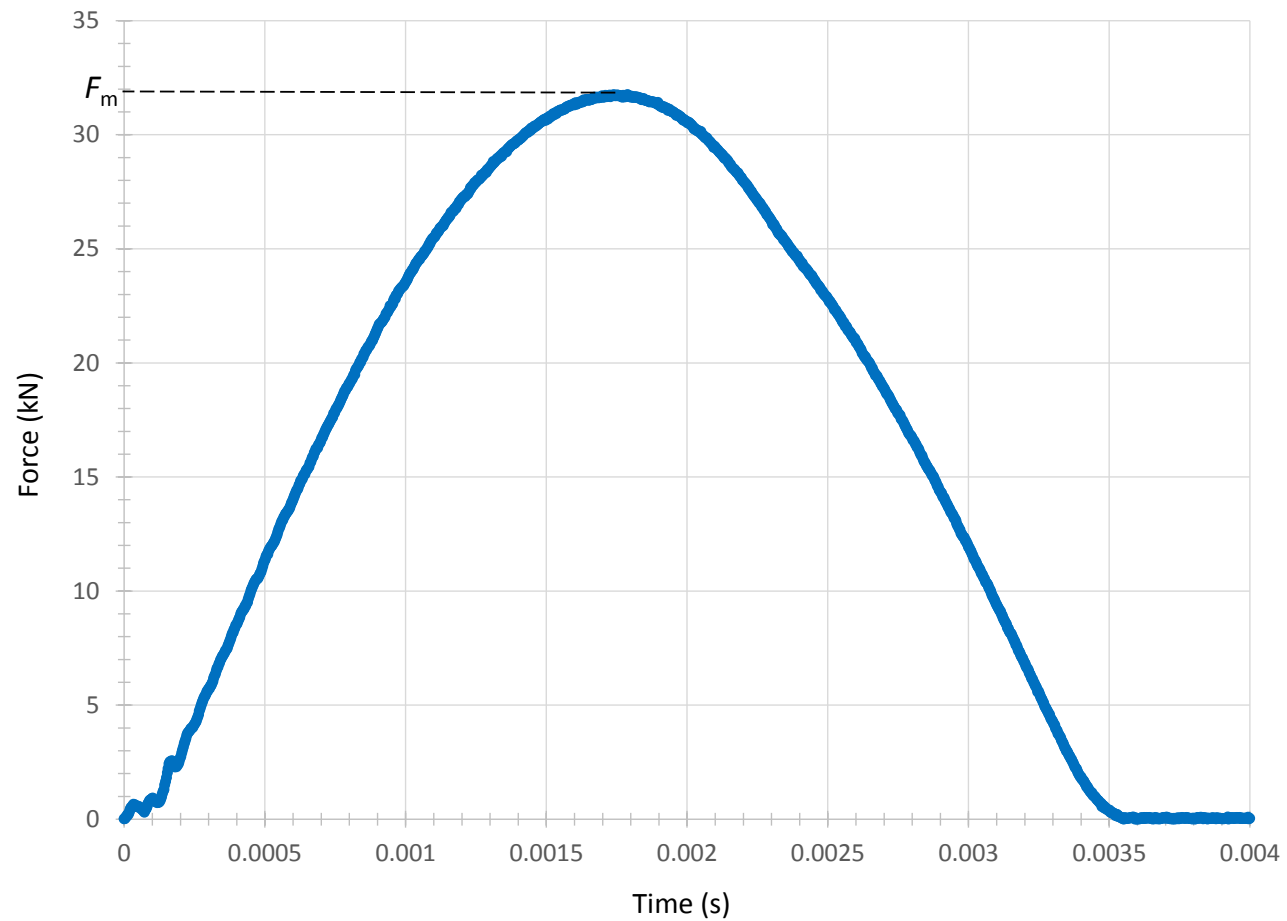

Figure 3 - Example of instrumented forceltime record for a low-blow test on an unnotched specimen with $10 \times 10 \mathrm{~mm}^{2}$ cross section (CVN-type).

\section{Method 2 [12]}

The available potential energy $W_{0}$ in the low-blow test is the sum of the elastic energy contributions from the machine $\left(W_{\mathrm{M}}\right)$ and the specimen $\left(W_{\mathrm{S}(\mathrm{u})}\right)$ :

$$
W_{0}=W_{M}+W_{S(u)}=\frac{1}{2} F_{m} d_{M}+\frac{1}{2} F_{m} d_{S},
$$

where: $\quad F_{\mathrm{m}}=$ maximum force (see Figure 3),

$d_{\mathrm{M}}=$ effective elastic deformation of the machine at maximum force, and $d_{\mathrm{S}}=$ specimen deflection (displacement) at maximum force.

For an elastic test, the relationship between force and deflection for the specimen is expressed as:

$$
F \cdot C_{S}=d_{S}
$$

which for the machine can be written as:

$$
F \cdot C_{M}=d_{M}
$$

Eqs. 6, 7, 8 can be reduced to:

$$
C_{M}=\frac{2 W_{0}}{F_{m}^{2}}-C_{S}
$$




\section{Method 3 [13]}

If we assume the interaction hammer/specimen to be a vibrating mass on a spring, the force/time record of the low-blow test becomes a half-oscillation of the system. The time $t$ corresponding to this half-cycle is related to the hammer mass $m$ and the machine/specimen compliance $C_{\exp }$ by:

$$
t=\pi \sqrt{m C_{\text {exp }}}
$$

which, based on eq. 5 , can be written as:

$$
t=\pi \sqrt{\left(m C_{M}+m C_{S}\right)},
$$

and finally reduces to:

$$
C_{M}=\frac{g}{\rho_{W}}\left(\frac{t}{\pi}\right)^{2}-C_{S},
$$

with: $g=$ acceleration of gravity $(\mathrm{m} / \mathrm{s})$ and $\rho_{\mathrm{w}}=$ effective hammer weight $(\mathrm{kg})$.

Ireland reports that typical values of $C_{\mathrm{M}}$ range between $0.0086 \mathrm{~mm} / \mathrm{kN}$ and 0.0114 $\mathrm{mm} / \mathrm{kN}$ [10]; for a specific machine, the three methods should yield $C_{\mathrm{M}}$ values which agree within $10 \%$ [14].

\section{Compliance measurements for the NIST Charpy machines}

In accordance with the approaches outlined above, we measured the compliance of four large-scale Charpy impact machines, all located at NIST in Boulder Colorado. In addition, we performed compliance measurements on a small-scale table-top machine, also located in the Boulder lab, used for instrumented impact tests on miniaturized specimens of two different configurations (KLST and RHS) [15].

For each machine, three instrumented low-blow tests were performed on unnotched specimens, whose dimensions had been previously measured by means of a calibrated caliper to a precision of $0.01 \mathrm{~mm}$. The results of the dimensional measurements are collected in Table 2, which also provides the values of the area moment of inertia $(I)$ and specimen compliance $\left(C_{\mathrm{S}(\mathrm{u})}\right)$ from eqs. 3 and 4 . Each cross section dimension $(B$ and $W$ ) was measured in three positions, and the average value was used in the calculations. 
Table 2 - Dimensional measurements and compliance values for the unnotched specimens used for the NIST machine compliance measurements. NOTE: in the table, $B$ and $W$ are the average values of the three separate measurements.

\begin{tabular}{|c|c|c|c|c|c|c|c|c|c|c|c|}
\hline Specimen & & Thickn & $(\mathrm{mm}$ & & & Widt & (mm) & & $I$ & $S$ & $C_{\mathbf{S}(\mathbf{u})}$ \\
\hline id & $\mathrm{B}_{1}$ & $\mathrm{~B}_{2}$ & $\mathrm{~B}_{3}$ & B & $\mathrm{W}_{1}$ & $\mathrm{~W}_{2}$ & $\mathrm{~W}_{3}$ & W & $\left(\mathrm{mm}^{4}\right)$ & $(\mathrm{mm})$ & $(\mathbf{m m} / \mathbf{k N})$ \\
\hline CVN-1 & 9.85 & 9.92 & 9.88 & 9.88 & 9.82 & 9.87 & 9.86 & 9.85 & 787.1018 & 40.00 & 0.0082 \\
\hline CVN-2 & 9.90 & 9.87 & 9.86 & 9.88 & 9.76 & 9.75 & 9.80 & 9.77 & 767.5609 & 40.00 & 0.0084 \\
\hline CVN-3 & 9.85 & 9.85 & 9.81 & 9.84 & 9.79 & 9.80 & 9.84 & 9.81 & 773.8802 & 40.00 & 0.0083 \\
\hline CVN-4 & 9.90 & 9.89 & 9.91 & 9.90 & 9.90 & 9.88 & 9.84 & 9.87 & 794.0454 & 40.00 & 0.0081 \\
\hline KLST-1 & 2.97 & 2.97 & 2.97 & 2.97 & 3.91 & 3.90 & 3.93 & 3.91 & 14.83255 & 22.07 & 0.0729 \\
\hline KLST-2 & 2.97 & 2.92 & 2.95 & 2.95 & 4.01 & 3.96 & 3.92 & 3.96 & 15.28733 & 22.07 & 0.0708 \\
\hline RHS-1 & 4.69 & 4.70 & 4.67 & 4.69 & 4.69 & 4.70 & 4.67 & 4.69 & 40.20453 & 19.30 & 0.0180 \\
\hline RHS-2 & 4.70 & 4.71 & 4.70 & 4.70 & 4.77 & 4.79 & 4.74 & 4.77 & 42.44914 & 19.30 & 0.0170 \\
\hline
\end{tabular}

The input parameters which were needed to calculate machine compliance in accordance with the three methods described in Section 2 are the following:

- $\quad$ mass of the pendulum hammer, $m(\mathrm{~N})$;

- potential energy, $W_{0}(\mathbf{J})$;

- hammer falling height, $h(\mathrm{~mm})$;

- hammer falling angle, $\alpha\left(^{\circ}\right)$; and

- impact velocity, $v(\mathrm{~m} / \mathrm{s})$.

The initial experimental compliance, $C_{\text {exp }}$, to be used for Method 1 (eq. 1), was obtained by linearly fitting the initial portion of the instrumented force/displacement test records, discarding any early oscillations arising from the first contact between hammer and specimens (see an example in Figure 4). The range to be linearly fitted was chosen subjectively by the author.

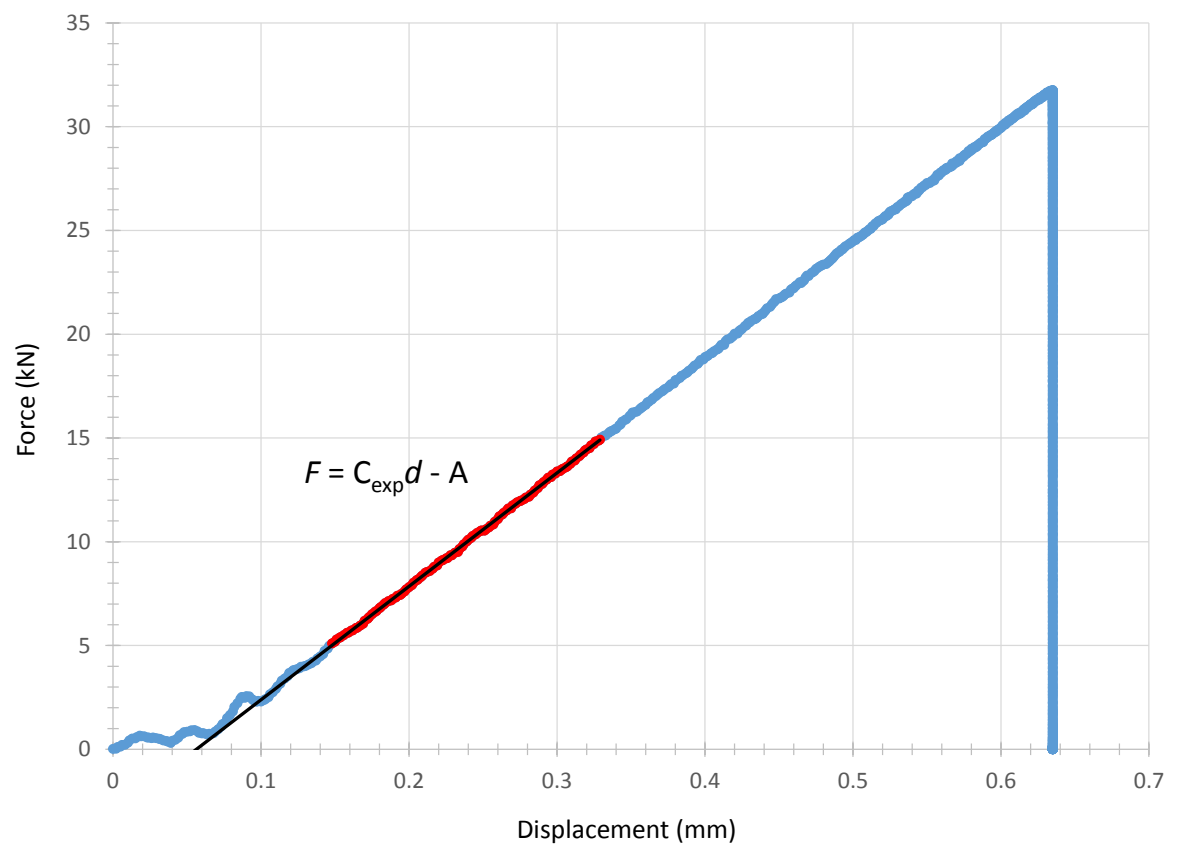

Figure 4 - Measurement of $C_{\text {exp }}$ from the instrumented force/displacement record. 
The maximum force, $F_{\mathrm{m}}$, to be used for Method 2 (eq. 9) was obtained by fitting the middle portion of the force/time record with a $2^{\text {nd }}$-order polynomial (Figure 5).

Finally, the time $t$ of the half cycle, to be used for Method 3 (eq. 12), was determined by first linearly fitting the initial and final part of the force/time record, and then calculating the distance between the two intercepts with the time axis (Figure 5).

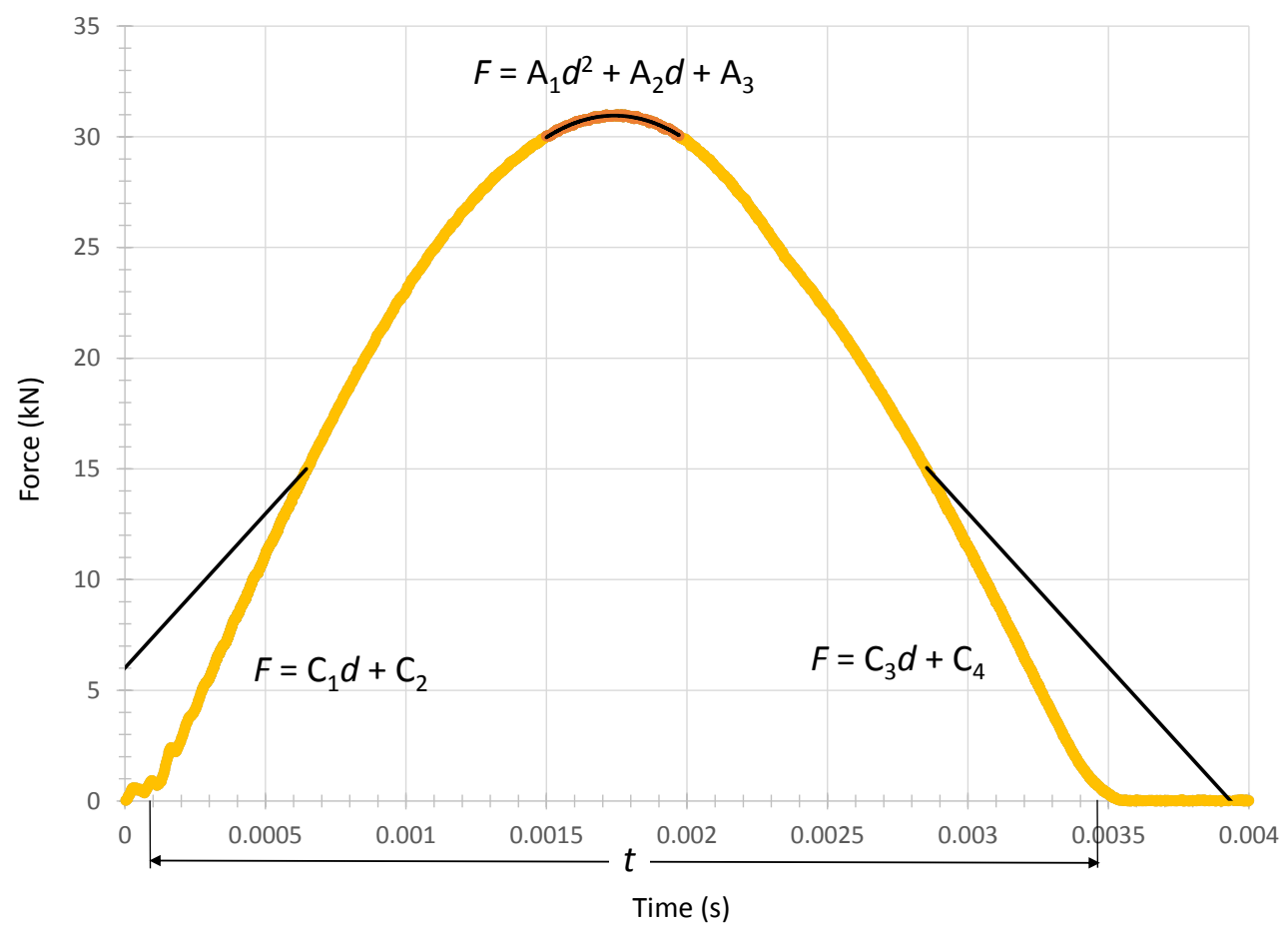

Figure 5 - Analysis of the force/time record for the determination of $F_{m}$ and $t$.

\subsection{TO2 machine (instrumented striker: JS1)}

This machine has a maximum potential energy of $357.91 \mathrm{~J}$, a maximum impact velocity of $5.12 \mathrm{~m} / \mathrm{s}$, and a hammer weight of $267.823 \mathrm{~N}$ (effective hammer mass $\rho_{\mathrm{w}}=27.31 \mathrm{~kg}$ ).

The three low-blow tests were performed on the unnotched specimen designated CVN-1 (Table 2). The remaining parameters used for the calculations of machine compliance are listed in Table 3.

Table 3 - Parameters used for the calculation of the compliance of machine TO2.

\begin{tabular}{|c|c|c|c|c|}
\hline $\begin{array}{c}\text { Low-blow } \\
\text { test \# }\end{array}$ & $\begin{array}{c}W_{0} \\
(\mathrm{~J})\end{array}$ & $\begin{array}{c}h \\
(\mathrm{~mm})\end{array}$ & $\begin{array}{c}\alpha \\
\left({ }^{\circ}\right)\end{array}$ & $\begin{array}{c}\mathrm{v} \\
(\mathrm{m} / \mathrm{s})\end{array}$ \\
\hline 1 & 8.72 & 32.58 & 15.46 & 0.80 \\
\hline 2 & 8.75 & 32.67 & 15.48 & 0.80 \\
\hline 3 & 8.73 & 32.58 & 15.46 & 0.80 \\
\hline
\end{tabular}

The result of the calculations, including intermediate steps such as experimental compliance, maximum force, and half-cycle time, are provided in Table 4, as well as average values and maximum deviations of individual test methods from the average of all methods. The maximum deviation between values calculated for each low-blow test and the average of all tests is also given. 
Table 4 - Results of compliance calculations for machine TO2.

\begin{tabular}{|c|c|c|c|c|c|c|c|c|}
\hline \multirow{2}{*}{$\begin{array}{c}\text { Low-blow } \\
\text { test \# }\end{array}$} & \multicolumn{2}{|c|}{ Method 1} & \multicolumn{2}{|c|}{ Method 2} & \multicolumn{2}{|c|}{ Method 3} & \multirow{2}{*}{$\begin{array}{c}\text { Average } \\
C_{\mathrm{M}, 1-3} \\
(\mathrm{~mm} / \mathrm{kN})\end{array}$} & \multirow{2}{*}{$\begin{array}{c}\text { Maximum } \\
\text { deviation }\end{array}$} \\
\hline & $\begin{array}{c}C_{\exp } \\
(\mathrm{mm} / \mathrm{kN})\end{array}$ & $\begin{array}{c}C_{\mathrm{M}, 1} \\
(\mathrm{~mm} / \mathrm{kN})\end{array}$ & $\begin{array}{c}F_{\mathrm{m}} \\
(\mathrm{kN})\end{array}$ & $\begin{array}{c}C_{\mathrm{M}, 2} \\
(\mathrm{~mm} / \mathrm{kN})\end{array}$ & $\begin{array}{c}t \\
(\mathrm{~ms}) \\
\end{array}$ & $\begin{array}{c}C_{\mathrm{M}, 3} \\
(\mathrm{~mm} / \mathrm{kN})\end{array}$ & & \\
\hline 1 & 0.01923 & 0.01105 & 29.23 & 0.01224 & 2.39 & 0.01302 & 0.01210 & $-8.7 \%$ \\
\hline 2 & 0.02036 & 0.01218 & 29.39 & 0.01208 & 2.41 & 0.01335 & 0.01254 & $6.7 \%$ \\
\hline 3 & 0.02146 & 0.01328 & 29.31 & 0.01213 & 2.41 & 0.01334 & 0.01292 & $6.6 \%$ \\
\hline Average & 0.02035 & 0.01217 & 29.31 & 0.01215 & 2.40 & 0.01324 & 0.01252 & $-3.3 \%$ \\
\hline \multicolumn{2}{|c|}{ Maximum deviation } & $-9.2 \%$ & & $0.7 \%$ & & $-1.6 \%$ & $-3.3 \%$ & \\
\hline
\end{tabular}

For machine TO2, all the methods provide reliable and consistent compliance values. Method 1 exhibits the largest scatter, caused by the scatter in the determination of the experimental compliance from the linear portion of the force/displacement test records.

The three methods (based on the average values from the three low-blow tests) yield compliance values well within $10 \%$ (as recommended by Ireland [10] and Turner [14]).

On the basis of our results, we can assume the average value of the three low-blow tests and the three calculation methods as the TO2 machine compliance at room temperature:

\section{$0.01252 \mathrm{~mm} / \mathrm{kN}$.}

\subsection{TO3 machine (instrumented striker: JS1)}

This machine has a maximum potential energy of $407.83 \mathrm{~J}$, a maximum impact velocity of $5.48 \mathrm{~m} / \mathrm{s}$, and a hammer weight of $266.3216 \mathrm{~N}$ (effective hammer mass $\rho_{\mathrm{w}}=27.18 \mathrm{~kg}$ ). The TO3 machine is structurally similar to TO2, and utilizes the same instrumented striker (JS-1).

The three low-blow tests were performed on the unnotched specimen designated CVN-3 (Table 2). The remaining parameters used for the calculations of machine compliance are listed in Table 5.

Table 5 - Parameters used for the calculation of the compliance of machine TO3.

\begin{tabular}{|c|c|c|c|c|}
\hline $\begin{array}{c}\text { Low-blow } \\
\text { test \# }\end{array}$ & $\begin{array}{c}W_{0} \\
(\mathrm{~J})\end{array}$ & $\begin{array}{c}h \\
(\mathrm{~mm})\end{array}$ & $\begin{array}{c}\alpha \\
\left({ }^{\circ}\right)\end{array}$ & $\begin{array}{c}\mathrm{v} \\
(\mathrm{m} / \mathrm{s})\end{array}$ \\
\hline 1 & 8.77 & 32.92 & 15.54 & 0.80 \\
\hline 2 & 8.91 & 33.47 & 15.67 & 0.81 \\
\hline 3 & 8.92 & 33.52 & 15.68 & 0.81 \\
\hline
\end{tabular}

The result of the calculations, including maximum deviations between methods and low-blow tests, are provided in Table 6.

Table 6-Results of compliance calculations for machine TO3.

\begin{tabular}{|c|c|c|c|c|c|c|c|c|}
\hline \multirow{2}{*}{$\begin{array}{c}\text { Low-blow } \\
\text { test \# }\end{array}$} & \multicolumn{2}{|c|}{ Method 1} & \multicolumn{2}{|c|}{ Method 2} & \multicolumn{2}{|c|}{ Method 3} & \multirow{2}{*}{$\begin{array}{c}\text { Average } \\
C_{\mathrm{M}, 1-3} \\
(\mathrm{~mm} / \mathrm{kN})\end{array}$} & \multirow{2}{*}{$\begin{array}{c}\text { Maximum } \\
\text { deviation }\end{array}$} \\
\hline & $\begin{array}{c}C_{\exp } \\
(\mathrm{mm} / \mathrm{kN})\end{array}$ & $\begin{array}{c}C_{\mathrm{M}, 1} \\
(\mathrm{~mm} / \mathrm{kN})\end{array}$ & $\begin{array}{c}F_{\mathrm{m}} \\
(\mathrm{kN})\end{array}$ & $\begin{array}{c}C_{\mathrm{M}, 2} \\
(\mathrm{~mm} / \mathrm{kN})\end{array}$ & $\begin{array}{c}t \\
(\mathrm{~ms})\end{array}$ & $\begin{array}{c}C_{\mathrm{M}, 3} \\
(\mathrm{~mm} / \mathrm{kN})\end{array}$ & & \\
\hline 1 & 0.02169 & 0.0133 & 30.48 & 0.01094 & 2.39 & 0.01298 & 0.01243 & $-12.0 \%$ \\
\hline 2 & 02111 & $\overline{012}$ & 30.48 & 01 & 2.38 & 01275 & 0.0 & $2 \%$ \\
\hline 3 & 0.02121 & 0.01288 & 30.58 & 0.01076 & 2.38 & 0.01276 & 0.01214 & $-11.0 \%$ \\
\hline Average & 0.02134 & 0.01301 & 30.51 & 0.01086 & 2.38 & 0.01283 & 0.01224 & $-11.2 \%$ \\
\hline \multicolumn{2}{|c|}{ Maximum deviation } & $2.7 \%$ & & $-0.9 \%$ & & $-1.6 \%$ & $1.6 \%$ & \\
\hline
\end{tabular}


For machine TO3, Method 2 provides lower values than Methods 1 and 3, with deviations systematically larger than $10 \%$. As in the case of machine TO2, Method 1 exhibits the largest scatter.

We see no reason to exclude any of the three methods from the calculations of machine compliance. Therefore, we can assume the average value of the three low-blow tests and the three calculation methods as the TO3 machine compliance at room temperature:

$0.01224 \mathrm{~mm} / \mathrm{kN}$.

\subsection{MPM-700 machine (instrumented striker: JS-1M)}

This machine has a maximum potential energy of $953.56 \mathrm{~J}$, a maximum impact velocity of $5.47 \mathrm{~m} / \mathrm{s}$, and a hammer weight of $625.84 \mathrm{~N}$ (effective hammer mass $\rho_{\mathrm{w}}=63.86 \mathrm{~kg}$ ).

The three low-blow tests were performed on the unnotched specimen designated CVN-2 (Table 2). The remaining parameters used for the calculations of machine compliance are listed in Table 7.

Table 7 - Parameters used for the calculation of the compliance of machine MPM-700.

\begin{tabular}{|c|c|c|c|c|}
\hline $\begin{array}{c}\text { Low-blow } \\
\text { test \# }\end{array}$ & $\begin{array}{c}W_{0} \\
(\mathrm{~J})\end{array}$ & $\begin{array}{c}h \\
(\mathrm{~mm})\end{array}$ & $\begin{array}{c}\alpha \\
\left({ }^{\circ}\right)\end{array}$ & $\begin{array}{c}\mathrm{v} \\
(\mathrm{m} / \mathrm{s})\end{array}$ \\
\hline 1 & 9.26 & 14.79 & 7.99 & 0.54 \\
\hline 2 & 8.76 & 13.99 & 7.77 & 0.52 \\
\hline 3 & 9.03 & 14.43 & 7.89 & 0.53 \\
\hline
\end{tabular}

The result of the calculations, including maximum deviations between methods and low-blow tests, are provided in Table 8.

Table 8 - Results of compliance calculations for machine MPM-700.

\begin{tabular}{|c|c|c|c|c|c|c|c|c|}
\hline \multirow{2}{*}{$\begin{array}{c}\text { Low-blow } \\
\text { test \# }\end{array}$} & \multicolumn{2}{|c|}{ Method 1} & \multicolumn{2}{|c|}{ Method 2} & \multicolumn{2}{|c|}{ Method 3} & \multirow{2}{*}{$\begin{array}{c}\text { Average } \\
C_{\mathrm{M}, 1-3-3} \\
(\mathrm{~mm} / \mathrm{kN})\end{array}$} & \multirow[b]{2}{*}{$\begin{array}{l}\text { Maximum } \\
\text { deviation }\end{array}$} \\
\hline & $\begin{array}{c}C_{\exp } \\
(\mathrm{mm} / \mathrm{kN})\end{array}$ & $\begin{array}{c}C_{\mathrm{M}, 1} \\
(\mathrm{~mm} / \mathrm{kN})\end{array}$ & $\begin{array}{c}F_{\mathrm{m}} \\
(\mathrm{kN})\end{array}$ & $\begin{array}{c}C_{\mathrm{M}, 2} \\
(\mathrm{~mm} / \mathrm{kN})\end{array}$ & $\begin{array}{c}t \\
(\mathrm{~ms})\end{array}$ & $\begin{array}{c}C_{\mathrm{M}, 3} \\
(\mathrm{~mm} / \mathrm{kN})\end{array}$ & & \\
\hline 1 & 0.01829 & 0.00990 & 31.72 & 0.01002 & 3.38 & 0.00972 & 0.00988 & $-1.6 \%$ \\
\hline 2 & 0.01805 & 0.00966 & 30.95 & 0.00989 & 3.38 & 0.00970 & 0.00975 & $1.4 \%$ \\
\hline 3 & 0.01808 & 0.00969 & 31.41 & 0.00991 & 3.38 & 0.00969 & 0.00976 & $1.6 \%$ \\
\hline Average & 0.01814 & 0.00975 & 31.36 & 0.00994 & 3.38 & 0.00970 & $\begin{array}{l}0.00980 \\
\end{array}$ & $-1.4 \%$ \\
\hline \multicolumn{2}{|c|}{ Maximum deviation } & $1.6 \%$ & & $-0.8 \%$ & & $0.1 \%$ & $0.8 \%$ & \\
\hline
\end{tabular}

For machine MPM-700, extremely consistent results and very low deviations (less than $2 \%$ ) were obtained for all methods and low-blow tests.

We can reliably assume the average value of the three low-blow tests and the three calculation methods as the MPM-700 machine compliance at room temperature:

$\mathbf{0 . 0 0 9 8 0 ~} \mathbf{~ m m} / \mathbf{k N}$. This machine is significantly less compliant (i.e., stiffer) than both TO2 and TO3. 


\section{$3.4 \quad$ T-K machine (instrumented striker: MPM-S-79)}

This machine has a maximum potential energy of $359.52 \mathrm{~J}$, a maximum impact velocity of $4.89 \mathrm{~m} / \mathrm{s}$, and the hammer mass is $m=295.87 \mathrm{~N}$ (effective hammer weight $\rho_{\mathrm{W}}=30.11 \mathrm{~kg}$ ).

The three low-blow tests were performed on the unnotched specimen designated CVN-4 (Table 2). The remaining parameters used for the calculations of machine compliance are listed in Table 9.

Table 9 - Parameters used for the calculation of the compliance of machine T-K.

\begin{tabular}{|c|c|c|c|c|}
\hline $\begin{array}{c}\text { Low-blow } \\
\text { test \# }\end{array}$ & $\begin{array}{c}W_{0} \\
(\mathrm{~J})\end{array}$ & $\begin{array}{c}h \\
(\mathrm{~mm})\end{array}$ & $\begin{array}{c}\alpha \\
\left(^{\circ}\right)\end{array}$ & $\begin{array}{c}\mathrm{v} \\
(\mathrm{m} / \mathrm{s})\end{array}$ \\
\hline 1 & 7.92 & 26.77 & 14.02 & 0.72 \\
\hline 2 & 8.54 & 28.86 & 14.56 & 0.75 \\
\hline 3 & 8.41 & 28.42 & 14.45 & 0.75 \\
\hline
\end{tabular}

The result of the calculations, including maximum deviations between methods and lowblow tests, are provided in Table 10.

Table 10 - Results of compliance calculations for machine T-K.

\begin{tabular}{|c|c|c|c|c|c|c|c|c|}
\hline \multirow[b]{2}{*}{$\begin{array}{c}\text { Low-blow } \\
\text { test \# }\end{array}$} & \multicolumn{2}{|c|}{ Method 1} & \multicolumn{2}{|c|}{ Method 2} & \multicolumn{2}{|c|}{ Method 3} & \multirow{2}{*}{$\begin{array}{c}\text { Average } \\
C_{\mathrm{M}, 1-3} \\
(\mathrm{~mm} / \mathrm{kN})\end{array}$} & \multirow[b]{2}{*}{$\begin{array}{c}\text { Maximum } \\
\text { deviation }\end{array}$} \\
\hline & $\begin{array}{c}C_{\exp } \\
(\mathrm{mm} / \mathrm{kN})\end{array}$ & $\begin{array}{c}C_{\mathrm{M}, 1} \\
(\mathrm{~mm} / \mathrm{kN})\end{array}$ & $\begin{array}{c}F_{\mathrm{m}} \\
(\mathrm{kN})\end{array}$ & $\begin{array}{c}C_{\mathrm{M}, 2} \\
(\mathrm{~mm} / \mathrm{kN})\end{array}$ & $\begin{array}{c}t \\
(\mathrm{~ms})\end{array}$ & $\begin{array}{c}C_{\mathrm{M}, 3} \\
(\mathrm{~mm} / \mathrm{kN})\end{array}$ & & \\
\hline 1 & 0.01542 & 0.00731 & 33.86 & 0.00570 & 2.27 & 0.00921 & 0.00741 & $24.3 \%$ \\
\hline 2 & 0.01753 & 0.00942 & 29.66 & 0.01131 & 2.28 & 0.00940 & 0.01004 & $12.6 \%$ \\
\hline 3 & 0.01478 & 0.00667 & 34.18 & 0.00628 & 2.27 & 0.00919 & 0.00738 & $-11.0 \%$ \\
\hline Average & 0.01591 & 0.00780 & 32.57 & 0.00776 & 2.27 & 0.00927 & 0.00828 & $21.3 \%$ \\
\hline \multicolumn{2}{|c|}{ Maximum deviation } & $20.8 \%$ & & $45.6 \%$ & & $-1.5 \%$ & $12.0 \%$ & \\
\hline
\end{tabular}

Examination of Table 10 reveals that for machine T-K, Methods 1 and 2 yield very large deviations between the three low-blow tests performed. In addition, all maximum deviations between individual methods are also larger than $10 \%$.

The instrumented striker used for the T-K machine has structural issues that require replacement of the instrumentation. The reliability of the static calibration of MPM-S-79 is therefore questionable, and as a consequence both Method 1 (which uses $C_{\exp }$, determined from the force/displacement record) and Method 2 (which uses the maximum force $F_{\mathrm{m}}$ ) cannot be used for machine compliance determination. On the other hand, Method 3 only uses a machine characteristic, such as $\rho_{\mathrm{w}}$, and the time-based parameter $t$ (see eq. 12). The low scatter obtained for Method 3 for the three low-blow tests corroborates this approach.

As a consequence, we will provisionally use the average value of Method 3 as the compliance of the T-K machine: $\mathbf{0 . 0 0 9 2 7} \mathbf{~ m m} / \mathbf{k N}$. Once the striker has been regaged, the machine compliance measurements will be repeated.

\subsection{Table-Top machine (instrumented striker: KLST)}

The Table-Top machine is a small-scale pendulum, used for testing miniaturized Charpy specimens. The machine, equipped with the hammer and instrumented striker for KLST specimens $(3 \mathrm{~mm} \times 4 \mathrm{~mm} \times 27 \mathrm{~mm})$, has a maximum potential energy of $50.15 \mathrm{~J}$, a maximum 
impact velocity of $3.50 \mathrm{~m} / \mathrm{s}$, and a hammer weight of $79.578 \mathrm{~N}$ (effective hammer mass $\rho_{\mathrm{W}}=$ $8.12 \mathrm{~kg}$ ). The instrumented striker for KLST specimens is designated MPM-S-68.

The three low-blow tests were performed on an unnotched specimen with nominal cross section dimensions of $3 \times 4 \mathrm{~mm}^{2}$ designated KLST-1 (Table 2). The remaining parameters used for the calculations of machine compliance are listed in Table 11.

Table 11 - Parameters used for the calculation of the compliance of the Table-Top machine with KLST hammer and striker.

\begin{tabular}{|c|c|c|c|c|}
\hline $\begin{array}{c}\text { Low-blow } \\
\text { test \# }\end{array}$ & $\begin{array}{c}W_{0} \\
(\mathrm{~J})\end{array}$ & $\begin{array}{c}h \\
(\mathrm{~mm})\end{array}$ & $\begin{array}{c}\alpha \\
\left({ }^{\circ}\right)\end{array}$ & $\begin{array}{c}\mathrm{v} \\
(\mathrm{m} / \mathrm{s})\end{array}$ \\
\hline 1 & 0.97 & 12.23 & 15.77 & 0.49 \\
\hline 2 & 0.98 & 12.27 & 15.79 & 0.49 \\
\hline 3 & 0.91 & 11.45 & 15.25 & 0.47 \\
\hline
\end{tabular}

The result of the calculations, including maximum deviations between methods and low-blow tests, are provided in Table 12.

Table 12 - Results of compliance calculations for the Table-Top machine with KLST hammer and striker.

\begin{tabular}{|c|c|c|c|c|c|c|c|c|}
\hline \multirow[b]{2}{*}{$\begin{array}{c}\text { Low-blow } \\
\text { test \# }\end{array}$} & \multicolumn{2}{|c|}{ Method 1} & \multicolumn{2}{|c|}{ Method 2} & \multicolumn{2}{|c|}{ Method 3} & \multirow{2}{*}{$\begin{array}{c}\text { Average } \\
C_{\mathrm{M}, 1-3} \\
(\mathrm{~mm} / \mathrm{kN})\end{array}$} & \multirow[b]{2}{*}{$\begin{array}{c}\text { Maximum } \\
\text { deviation }\end{array}$} \\
\hline & $\begin{array}{c}C_{\exp } \\
(\mathrm{mm} / \mathrm{kN})\end{array}$ & $\begin{array}{c}C_{\mathrm{M}, 1} \\
(\mathrm{~mm} / \mathrm{kN})\end{array}$ & $\begin{array}{c}F_{\mathrm{m}} \\
(\mathrm{kN})\end{array}$ & $\begin{array}{c}C_{\mathrm{M}, 2} \\
(\mathrm{~mm} / \mathrm{kN})\end{array}$ & $\begin{array}{c}t \\
(\mathrm{~ms})\end{array}$ & $\begin{array}{c}C_{\mathrm{M}, 3} \\
(\mathrm{~mm} / \mathrm{kN})\end{array}$ & & \\
\hline 1 & 0.15158 & 0.07864 & 3.48 & 0.08770 & 3.69 & 0.09686 & 0.08773 & $10.4 \%$ \\
\hline 2 & 0.15031 & 0.07736 & 3.46 & 0.08971 & 3.67 & 0.09523 & 0.08744 & $-11.5 \%$ \\
\hline 3 & 0.14979 & 0.07684 & 3.39 & 0.08573 & 3.68 & 0.09604 & 0.08620 & $-12.1 \%$ \\
\hline Average & 0.15056 & 0.07761 & 3.44 & 0.08771 & 3.68 & 0.09604 & 0.08712 & $-10.9 \%$ \\
\hline \multicolumn{2}{|c|}{ Maximum deviation } & $1.3 \%$ & & $-2.3 \%$ & & $0.9 \%$ & $-1.1 \%$ & \\
\hline
\end{tabular}

It is interesting to note that the deviations between the three methods are larger than the repeatability between the three low-blow tests.

We find no technical reason to exclude any of the three methods from the calculations of machine compliance. Therefore, we can assume the average value of the three low-blow tests and the three calculation methods as the room temperature compliance of the Table-Top machine with KLST hammer and striker: 0.08712 mm/kN.

We note that the compliance of this small-scale machine is significantly larger than any of the larger-scale (higher capacity) Charpy machines considered in this study.

\subsection{Table-Top machine (instrumented striker: RHS)}

The Table-Top machine, equipped with the hammer and instrumented striker for RHS specimens $(4.83 \mathrm{~mm} \times 4.83 \mathrm{~mm} \times 24.13 \mathrm{~mm})$, has a maximum potential energy of $50.80 \mathrm{~J}$, a maximum impact velocity of $3.50 \mathrm{~m} / \mathrm{s}$, and a hammer weight of $80.467 \mathrm{~N}$ (effective hammer mass $\rho_{\mathrm{W}}=8.21 \mathrm{~kg}$ ). The instrumented striker for RHS specimens is designated MPM-S-67.

The three low-blow tests were performed on an unnotched specimen with nominal cross section dimensions of $3 \times 4 \mathrm{~mm}^{2}$ designated RHS-1 (Table 2). The remaining parameters used for the calculations of machine compliance are listed in Table 13. 
Table 13 - Parameters used for the calculation of the compliance of the Table-Top machine with RHS hammer and striker.

\begin{tabular}{|c|c|c|c|c|}
\hline $\begin{array}{c}\text { Low-blow } \\
\text { test \# }\end{array}$ & $\begin{array}{c}W_{0} \\
(\mathrm{~J})\end{array}$ & $\begin{array}{c}h \\
(\mathrm{~mm})\end{array}$ & $\begin{array}{c}\alpha \\
\left(^{\circ}\right)\end{array}$ & $\begin{array}{c}\mathrm{v} \\
(\mathrm{m} / \mathrm{s})\end{array}$ \\
\hline 1 & 1.00 & 12.42 & 15.89 & 0.49 \\
\hline 2 & 1.00 & 12.48 & 15.93 & 0.49 \\
\hline 3 & 0.97 & 12.07 & 15.66 & 0.49 \\
\hline
\end{tabular}

The result of the calculations, including maximum deviations between methods and low-blow tests, are provided in Table 14.

Table 14 - Results of compliance calculations for the Table-Top machine with RHS hammer and striker.

\begin{tabular}{|c|c|c|c|c|c|c|c|c|}
\hline \multirow[b]{2}{*}{$\begin{array}{c}\text { Low-blow } \\
\text { test \# }\end{array}$} & \multicolumn{2}{|c|}{ Method 1} & \multicolumn{2}{|c|}{ Method 2} & \multicolumn{2}{|c|}{ Method 3} & \multirow{2}{*}{$\begin{array}{c}\text { Average } \\
C_{\mathrm{M}, 1-3} \\
(\mathrm{~mm} / \mathrm{kN})\end{array}$} & \multirow{2}{*}{$\begin{array}{c}\text { Maximum } \\
\text { deviation }\end{array}$} \\
\hline & $\begin{array}{c}C_{\exp } \\
(\mathrm{mm} / \mathrm{kN})\end{array}$ & $\begin{array}{c}C_{\mathrm{M}, 1} \\
(\mathrm{~mm} / \mathrm{kN})\end{array}$ & $\begin{array}{c}F_{\mathrm{m}} \\
(\mathrm{kN})\end{array}$ & $\begin{array}{c}C_{\mathrm{M}, 2} \\
(\mathrm{~mm} / \mathrm{kN})\end{array}$ & $\begin{array}{c}t \\
(\mathrm{~ms})\end{array}$ & $\begin{array}{c}C_{\mathrm{M}, 3} \\
(\mathrm{~mm} / \mathrm{kN})\end{array}$ & & \\
\hline 1 & 0.04384 & 0.02584 & 6.56 & 0.02851 & 1.96 & 0.02961 & 0.02798 & $-7.7 \%$ \\
\hline 2 & 0.04303 & 0.02504 & 6.78 & 0.02574 & 1.95 & 0.02870 & 0.02649 & $7.9 \%$ \\
\hline 3 & 0.04310 & 0.02510 & 6.67 & 0.02564 & 1.94 & 0.02849 & 0.02641 & $7.1 \%$ \\
\hline Average & 0.04332 & 0.02533 & 6.67 & 0.02663 & 1.95 & 0.02893 & 0.02696 & $3.8 \%$ \\
\hline \multicolumn{2}{|c|}{ Maximum deviation } & $2.0 \%$ & & $7.1 \%$ & & $2.3 \%$ & $7.3 \%$ & \\
\hline
\end{tabular}

All the deviations calculated between different methods or different tests are lower than $10 \%$, and therefore no technical reason can be found to exclude any of the three methods for machine compliance calculation. The average value of the three low-blow tests and the three calculation methods can be assumed to represent the room temperature compliance of the Table-Top machine with RHS hammer and striker: $0.02696 \mathbf{~ m m} / \mathbf{k N}$.

We note that, based on our compliance measurements, this small-scale machine is more than three times stiffer when equipped with the RHS hammer and striker than when equipped for testing KLST specimens, even though the hammer masses are only marginally different $(8.12 \mathrm{~kg}$ and $8.21 \mathrm{~kg}$ ). 


\section{Summary of compliance values for the NIST Charpy machines}

Based on the calculations detailed above, Table 15 summarizes the values of machine compliance, $C_{\mathrm{M}}$, at room temperature for the NIST impact testing machines, and the expected values of experimental compliance

$$
C_{\exp }=C_{S}+C_{M}
$$

where specimen compliance, $C_{\mathrm{S}}$, was calculated by means of eq. 1 assuming nominal dimensions for both full-size (CVN) and miniaturized (KLST or RHS) Charpy specimens. The values of $C_{\exp }$ in Table 15 are the approximate values one should expect to obtain when analyzing the linear portion of an instrumented force/displacement record (at room temperature), for instance when determining the force at general yield.

The calculated values of machine compliance for the large-scale machines (TO2, TO3, MPM-700, and T-K) are close to the range indicated by Ireland in [10], i.e., $0.0086 \mathrm{~mm} / \mathrm{kN}$ to $0.0114 \mathrm{~mm} / \mathrm{kN}$.

Table 15 - Summary of machine and experimental compliances for the NIST instrumented Charpy systems.

\begin{tabular}{|c|c|c|c|c|}
\hline $\begin{array}{c}\text { Impact } \\
\text { machine }\end{array}$ & $\begin{array}{c}\text { Instrumented } \\
\text { striker }\end{array}$ & $\begin{array}{c}C_{\mathrm{M}} \\
(\mathrm{mm} / \mathrm{kN})\end{array}$ & $\begin{array}{c}\text { Specimen } \\
\text { type }\end{array}$ & $\begin{array}{c}C_{\text {exp }} \\
(\mathrm{mm} / \mathrm{kN})\end{array}$ \\
\hline TO2 & JS1 & 0.01252 & CVN & 0.02399 \\
\hline TO3 & JS1 & 0.01224 & CVN & 0.02370 \\
\hline MPM-700 & JS-1M & 0.00980 & CVN & 0.02126 \\
\hline T-K & MPM-S-79 & 0.00927 & CVN & 0.02074 \\
\hline \multirow{2}{*}{ Table-Top } & MPM-S-68 & 0.08712 & KLST & 0.16690 \\
\cline { 2 - 5 } & MPM-S-67 & 0.02696 & RHS & 0.05069 \\
\hline
\end{tabular}

An interesting observation emerges from the examination of Table 15, in that machine compliance appears to be independent of machine capacity or hammer mass. To substantiate this statement, we remark that TO2 and TO3 have approximately the same compliance, even though TO3 has $14 \%$ higher capacity (potential energy). Even more significant is the fact that the T-K machine, whose capacity is less than $40 \%$ that of the MPM-700 machine, has very similar compliance. Incidentally, the T-K machine is the only one which has a C-type hammer and Ishaped beam, whereas all the remaining large-scale pendulums have U-type hammers and hollow-tube beams. Machine design and hammer type might therefore play a significant role in determining the compliance of a Charpy machine.

Oftentimes, Charpy tests are performed in a range of temperatures, for example when determining ductile-to-brittle transition temperatures for a material. In this case, values of experimental compliance at different test temperatures are useful for the experimentalist who analyzes the instrumented test records. In Annex 1, we have collected such values for all the NIST instrumented Charpy systems, for temperatures ranging from $-180{ }^{\circ} \mathrm{C}$ to $300{ }^{\circ} \mathrm{C}$, and for all the possible Charpy specimen types that can be tested on that system (full-size, sub-size, or 
miniaturized). Prior knowledge of the elastic slope that should be measured can help the analyst to select the optimal elastic fitting range when determining the point of general yield.

\section{Use of machine compliance for the dynamic calibration of Charpy instrumented strikers}

The conventional procedure for calibrating an instrumented Charpy striker, i.e. establishing the analytical relationship between force applied to the striker and strain-gage response, is a static calibration, preferably performed with the striker built into the hammer assembly. By applying different values of force to the striker in a configuration similar to the striker/specimen interaction during a test, the corresponding values of electrical output from the strain-gages are recorded and eventually fitted as a function of applied force.

The knowledge of the compliance of a Charpy machine offers an alternative approach to what Ireland called "dynamic calibration of an instrumented tup" [10]. The principle consists in matching a calculated peak impulse force, from an elastic low-blow test, with that obtained from the instrumented signal.

If the impact is entirely elastic, the maximum force is calculated from the following relationship, which is valid for elastic energy absorption:

$$
F_{m}=\sqrt{\frac{2 W_{0}}{C_{M}+C_{S}}}
$$

where $W_{0}$ is the maximum available kinetic energy. In principle, multiple values of $F_{\mathrm{m}}$ can be verified by varying the initial potential energy $W_{0}$ and therefore establishing the relationship between applied force and strain-gage output. Obviously, care must be exercised to avoid plastic deformation at higher force values.

For the Charpy test systems (i.e., impact machines + instrumented strikers) considered in this investigation, the dynamic conversion factors listed in Table 16 were obtained by substituting in eq. 14 the values of $W_{0}, C_{\mathrm{M}}, C_{\mathrm{S}}$ obtained in the previous sections. The table compares dynamic conversion factors $\left(C_{\text {dyn }}\right)$ to the static conversion factors $\left(C_{\text {stat }}\right)$ previously obtained from statically calibrating the instrumented strikers, and also provides the percent differences between the two conversion factors.

Table 16 - Comparison between dynamic and static conversion factors for NIST instrumented Charpy systems.

\begin{tabular}{|c|c|c|c|c|}
\hline $\begin{array}{c}\text { Charpy } \\
\text { machine }\end{array}$ & $\begin{array}{c}\text { Instrumented } \\
\text { striker }\end{array}$ & $\begin{array}{c}C_{\text {dyn }} \\
(\mathrm{kN} / \mathrm{V})\end{array}$ & $\begin{array}{c}C_{\text {stat }} \\
(\mathrm{kN} / \mathrm{V})\end{array}$ & $\begin{array}{c}\Delta C \\
(\%)\end{array}$ \\
\hline TO2 & JS1 & 9.9336 & 10.188 & -2.5 \\
\hline TO3 & JS1 & 9.7021 & 10.188 & -4.8 \\
\hline MPM-700 & JS-1M & 8.1622 & 8.2166 & -0.7 \\
\hline T-K & MPM-S-79 & 10.8708 & 11.4110 & -4.7 \\
\hline \multirow{2}{*}{ Table-Top } & MPM-S-68 & 0.8701 & 0.8924 & -2.5 \\
\cline { 2 - 5 } & MPM-S-67 & 2.1820 & 2.2379 & -2.5 \\
\hline
\end{tabular}

The dynamic conversion factors are systematically lower than the corresponding static conversion factors, with differences in all cases lower than $5 \%$. The small difference $(2.4 \%)$ 
between the values of $C_{\text {dyn }}$ calculated for the JS1 striker when assembled on the TO2 machine and on the TO3 machine is only due to experimental uncertainties associated to the determination of the various parameters in eq. 14 .

\section{Conclusions}

The compliance of all the instrumented Charpy systems (impact machines + instrumented strikers + acquisition systems) located at NIST in Boulder was measured by means of low-blow elastic tests on unnotched Charpy-type specimens. The instrumented force/time and force/displacement records of these low-blow tests were analyzed in accordance with the analytical procedure proposed by D. Ireland in a fundamental publication from 1974 [10].

For most Charpy systems, machine compliance can be obtained as the average of three separate values based on different analytical methods, and the expectation is that these three methods would provide compliance values which agree within $10 \%$. This was found to be the case for only half of the investigated NIST Charpy systems (machines + acquisition system). In most cases, good repeatability was found when comparing results for the three low-blow tests that were performed on each of the machines.

It was observed that machine compliance does not depend on initial potential energy or hammer weight, but on the structural characteristics of the machine and the hammer design (striker and beam).

Knowledge of the machine compliance, and therefore of the elastic slope that should be measured from the early portion of an instrumented Charpy test record, is expected to increase the accuracy in the determination of the point of general yield.

Machine compliance can also be used for calculating the conversion factor between the output of the instrumented striker and the applied force. For the NIST Charpy systems, these dynamic conversion factors are systematically lower than those established by statically calibrating the strikers, although the difference is always lower than $5 \%$. 


\section{References}

[1] D. W. Dunn, "A Photographic Impact Testing Machine for Measuring the Varying Intensity of an Impulsive Force," Journal of the Franklin Institute, Vol. CXLIV, No. 5, Nov 1897, pp. 321-348.

[2] S. B. Russell, "Experiments with a New Machine for Testing Materials by Impact," Transactions, American Society of Civil Engineers, Vol. 39, No. 826, 1898, pp. 237-250.

[3] M. P. Manahan and T. A. Siewert, "The History of Instrumented Impact Testing," Journal of ASTM International, Vol. 3, No. 2, February 2006.

[4] ISO 14556:2000, "Steel -- Charpy V-notch pendulum impact test -- Instrumented test method," International Standards Organization.

[5] ASTM E2298-13a, "Standard Test Method for Instrumented Impact Testing of Metallic Materials," ASTM Book of Standards, Vol. 03.01, 2014.

[6] ASTM E1820-13, "Standard Test Method for Measurement of Fracture Toughness," ASTM Book of Standards, Vol. 03.01, 2014.

[7] H. J. Saxton, D. R. Ireland, and W. L. Server, "Analysis and Control of Inertial Effects During Instrumented Impact Testing," Instrumented Impact Testing, ASTM STP 563, T. S. DeSisto, Ed., American Society for Testing and Materials, Philadelphia PA, 1974, pp. 50-73.

[8] W. L. Server, "General Yielding of Charpy V-Notch and Precracked Charpy Specimens," Journal of Engineering Materials and Technology, Vol. 100, Apr 1978, pp. 183-187.

[9] R. K. Nanstad and M. A. Sokolov, "Charpy Impact Test Results on Five Materials and NIST Verification Specimens Using Instrumented 2-mm and 8-mm Strikers," Pendulum Impact Machines: Procedures and Specimens for Verification, ASTM STP 1248, T. A.

Siewert and A. K. Schmieder, Eds., American Society for Testing and Materials, Philadelphia PA, 1995, pp. 111-139.

[10] D. R. Ireland, "Procedures and Problems Associated with Reliable Control of the Instrumented Impact Test," Instrumented Impact Testing, ASTM STP 563, T. S. DeSisto, Ed., American Society for Testing and Materials, Philadelphia PA, 1974, pp. 3-29.

[11] K. R. Iyer and R. B. Miclot, "Instrumented Charpy Testing for Determination of the J-Integral,” Instrumented Impact Testing, ASTM STP 563, T. S. DeSisto, Ed., American Society for Testing and Materials, Philadelphia PA, 1974, pp. 146-165.

[12] W. R. Server and D. R. Ireland, "Nonstandard Test Techniques Utilizing the Instrumented Charpy and Izod Test," Instrumented Impact Testing, ASTM STP 563, T. S. DeSisto, Ed., American Society for Testing and Materials, Philadelphia PA, 1974, pp. 74-91.

[13] A. H. Priest and M. J. May, "Fracture Toughness Testing in Impact," NDACSS A86, 1969.

[14] C. E. Turner, P. Kennish, L. E. Culver, and J. C. Radon, "A Study of the Mechanics of Notched-Bar Impact Tests,” Imperial College Department of Mechanical Engineering, Final Report to Navy Department, Advisory Committee on Structural Steels, June 1970.

[15] E. Lucon, "Miniaturized Charpy Specimens for the Indirect Verification of Small-Scale Charpy Machines: Initial Qualification Phase," NIST Technical Note 1562-1, July 2012. 


\section{ANNEX 1}

\section{Tables of Experimental Compliance Values for the NIST Charpy Systems}




\begin{tabular}{|c|c|c|c|c|c|c|c|c|c|c|c|c|c|}
\hline \multirow{2}{*}{\multicolumn{2}{|c|}{$\begin{array}{r}\text { Specimen type: } \\
\text { Thickness } \mathrm{B}(\mathrm{mm})=\end{array}$}} & \multicolumn{2}{|c|}{ CVN } & \multicolumn{2}{|c|}{$3 / 4-5 S$} & \multicolumn{2}{|c|}{$2 / 3-S S$} & \multicolumn{2}{|c|}{$1 / 2$-SS } & \multicolumn{2}{|c|}{$1 / 3-S S$} & \multicolumn{2}{|c|}{ 1/4-SS } \\
\hline & & \multicolumn{2}{|c|}{10} & \multicolumn{2}{|c|}{7.5} & \multicolumn{2}{|c|}{6.67} & \multicolumn{2}{|c|}{5} & \multicolumn{2}{|c|}{3.33} & \multicolumn{2}{|c|}{2.5} \\
\hline & $\mathrm{nS}(\mathrm{mm})=$ & & & & & & & & & & & & \\
\hline & $\mathrm{h} W(\mathrm{~mm})=$ & 1 & & & & & & & & & & & \\
\hline Notch & th $\mathrm{a}(\mathrm{mm})=$ & & & & & & & & & & & & \\
\hline & $\mathrm{a} / \mathrm{W}=$ & 0 & & & & & & & & & & & \\
\hline & $f(a / W)=$ & 0.943 & 3584 & 0.94 & 3584 & 0.94 & 3584 & 0.94 & 3584 & 0.94 & 3584 & 0.94 & 3584 \\
\hline & & & & $3 / 4$ & SS & & -SS & & -SS & & -SS & & \\
\hline T & E & $C_{s}$ & $C_{\text {exp }}$ & $\mathrm{C}_{\mathrm{s}}$ & $C_{\text {exp }}$ & $\mathrm{C}_{\mathrm{s}}$ & $C_{\text {exp }}$ & $\mathrm{C}_{\mathrm{s}}$ & $C_{\text {exp }}$ & $\mathrm{C}_{\mathrm{s}}$ & $\mathrm{C}_{\text {exp }}$ & & $C_{\text {exp }}$ \\
\hline$\left({ }^{\circ} \mathrm{C}\right)$ & $\left(\mathrm{N} / \mathrm{mm}^{2}\right)$ & $(\mathrm{mm}$ & (kN) & $(\mathrm{mm}$ & (kN) & $(\mathrm{mm}$ & (kN) & $(\mathrm{mm}$ & (kN) & $(\mathrm{m}$ & (kN) & & \\
\hline-180 & 217800 & 0.01083 & 0.02335 & 0.01444 & 0.02696 & 0.01624 & 0.02876 & 0.02166 & 0.03418 & 0.03248 & 0.04500 & 0.04331 & 0.05583 \\
\hline-175 & 217500 & 0.01084 & 0.02336 & 0.01446 & 0.02698 & 0.01626 & 0.02878 & 0.02169 & 0.03421 & .03253 & 0.04505 & 1.04337 & 0.05589 \\
\hline-170 & 217200 & 0.01086 & 0.02338 & 0.01448 & 0.02700 & 0.01629 & 0.02881 & 0.02172 & 0.03424 & 0.03257 & 0.04509 & 0.04343 & 0.05595 \\
\hline-165 & 216900 & 0.01087 & 0.02339 & 0.01450 & 0.02702 & 0.01631 & 0.02883 & 0.02175 & 0.03427 & 0.03262 & 0.04514 & 0.04349 & 0.05601 \\
\hline-160 & 216600 & 0.01089 & 0.02341 & 0.01452 & 0.02704 & 0.01633 & 0.02885 & 0.02178 & 0.03430 & 0.03266 & 0.04518 & .04355 & 0.05607 \\
\hline-155 & 216300 & 0.01090 & 0.02342 & 0.01454 & 0.02706 & 0.01636 & 0.02887 & 0.02181 & 0.03433 & 0.03271 & 0.04523 & 0.04361 & 0.05613 \\
\hline-150 & 000 & 0.01092 & 0.02344 & 0.01456 & 0.02708 & 0.01638 & 0.02890 & 0.02184 & 0.03436 & 0.03276 & 0.04527 & 0.04367 & 0.05619 \\
\hline-145 & 5700 & 0.01093 & 0.02345 & 0.01458 & 0.02710 & 0.01640 & 0.02892 & 0.02187 & 03439 & 0.03280 & 0.04532 & 0.04373 & 0.05625 \\
\hline-140 & 5400 & 0.01095 & 0.02347 & 0.01460 & 0.02712 & 0.01642 & 0.02894 & 0.02190 & .03442 & .03285 & 0.04537 & 0.04380 & 0.05631 \\
\hline-135 & 215100 & 0.01096 & 0.02348 & 0.01462 & 0.02714 & 0.01645 & 0.02897 & 0.02193 & 0.03445 & .03289 & 0.04541 & .04386 & 0.05638 \\
\hline-130 & 214800 & 0.01098 & 0.02350 & 0.01464 & 0.02716 & 0.01647 & 0.02 & 0.02196 & 0.03448 & 0.03294 & 0.04546 & 0.04392 & 0.05644 \\
\hline-125 & 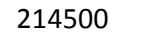 & 0.01099 & 0.0 & 0.01466 & 0.02718 & 0.01649 & 0.02 & 0.02199 & 51 & 98 & 50 & 0.0 & 0.05650 \\
\hline-120 & 200 & 0.01101 & 0.02353 & 0.01468 & 0.02720 & 0.01652 & 0.02903 & 0.02202 & 0.03454 & .03303 & 0.0 & .04404 & 0.05656 \\
\hline-115 & 3900 & 0.01103 & 0.02354 & 0.01470 & 0.02722 & 0.01654 & 0.02906 & 0.02205 & 03457 & .03308 & 60 & .04410 & 0.05662 \\
\hline-110 & 600 & 0.01104 & 0.02356 & 0.01472 & 0.02724 & 0.01656 & 0.02908 & 0.02208 & 0.03460 & .03312 & 64 & 16 & 0.05668 \\
\hline-105 & 2 & 0.01106 & 0.02358 & 0.01474 & 0.02726 & 0.01659 & 0. & 0.02 & 63 & 17 & 69 & 23 & 0.05675 \\
\hline-100 & & 1107 & 9 & 0.01 & 0.02728 & 0.01 & & 0.02 & & 0.0 & & & 0.0 \\
\hline-95 & 700 & 0.01109 & 1 & 0.01478 & 0.02730 & .01663 & 0.0 & 0.02218 & 70 & 0.03326 & 78 & 0.0 & 0.05687 \\
\hline-90 & 400 & 0.01110 & 0.02362 & 0.01480 & 0.02732 & 0.01666 & 0.02917 & 0.02221 & .03473 & 0.03331 & 83 & 0.0 & 0.05693 \\
\hline-85 & & 1112 & 0.02364 & 0.01483 & 0.02734 & 0.01668 & 20 & 02224 & 76 & 36 & & & 0.05700 \\
\hline-80 & 80 & 0.01114 & 0.02365 & 0.01485 & 0.02737 & 0.01670 & 0.02922 & 0.02227 & 03479 & 41 & 92 & .04454 & 0.05706 \\
\hline-75 & & 5 & & 0.01 & 9 & 3 & & 30 & & & & & 0.0 \\
\hline-70 & 2 & 117 & 0.02 & 39 & 0.02 & 75 & 27 & 33 & 85 & 50 & 02 & 0.0 & 0.05719 \\
\hline-65 & 00 & 1118 & 0.02370 & 0.01491 & 0.02743 & 0.01677 & 0.02 & 0.02237 & 188 & 355 & 607 & .04473 & 0.05725 \\
\hline-60 & & 1120 & & & 0.02745 & 0.01680 & & 02240 & & & & 79 & 0.05731 \\
\hline-55 & & 0.01121 & 0.02373 & 0.014 & & 0.01 & & & & & & .04486 & 0.05738 \\
\hline-50 & & & & & & & & & & & & & 0.05744 \\
\hline-45 & & & & & & 0.0 & & & & & & & \\
\hline-40 & 400 & 126 & 8 & 2 & 0.02 & .01689 & 1 & 02253 & 04 & 79 & 31 & 05 & 0.05757 \\
\hline-35 & 9100 & 1128 & 0.02380 & 01504 & 0.02756 & 0.01692 & 0.02944 & 0.02256 & 03508 & 03384 & 36 & .04512 & 0.05763 \\
\hline-30 & 800 & 0.01130 & 0.02381 & .01506 & 0.02758 & 0.01694 & & 0.02259 & 3511 & 03389 & & 18 & 0.05770 \\
\hline-25 & 208500 & 0.01131 & & & & & & & & & & & 0.05776 \\
\hline-20 & & & & & & & & & & & & & \\
\hline-15 & & & & & & 22 & & & & & & & \\
\hline-10 & 600 & 136 & 0.02388 & 5 & 0.02 & 0.01704 & 56 & 02272 & 24 & 03408 & 60 & 44 & 0.05796 \\
\hline-5 & 300 & 1138 & 0.02390 & 01517 & 0.02769 & 0.01707 & 8 & 02275 & 27 & 03413 & & 51 & 0.05803 \\
\hline 0 & 207000 & 139 & 0.02391 & 19 & 0.02771 & 0.01709 & & 0.02279 & & 418 & & 57 & 809 \\
\hline 5 & & & & & & & & & & & & & \\
\hline 10 & & & & & & & & & & & & & \\
\hline 15 & & 44 & & & & 0.0 & & 0.02289 & & 433 & & .04577 & 829 \\
\hline 20 & & 146 & 8 & 8 & 0. & 0.01719 & 1 & 0.02292 & & & & .04584 & \\
\hline 21 & 740 & 146 & & 8 & & 0.01719 & & 93 & & & & & 337 \\
\hline 22 & 205680 & 0.01147 & 0.02399 & 0.01529 & 0.02781 & 0.01720 & 0.02972 & 0.02293 & 03545 & 0.03440 & 0.04692 & 0.04587 & 0.05838 \\
\hline 23 & 205620 & 1147 & & 0.01529 & & 0.01720 & & & & & & & \\
\hline 24 & 560 & 147 & & & & & & & & & & & \\
\hline 25 & & 148 & & 30 & & 01721 & & 295 & & 3443 & & .04591 & 0.05842 \\
\hline 30 & 200 & 149 & 0.02401 & 0.01532 & 0.02784 & 0.01724 & 0.02976 & 0.02299 & 0.03551 & 0.03448 & 0.04700 & 0.04597 & 0.05849 \\
\hline 35 & 204900 & 0.01151 & 0.02403 & 0.01535 & 0.02787 & 0.01726 & 0.02978 & 0.02302 & 0.03554 & 0.03453 & 0.04705 & 0.04604 & 0.0585 \\
\hline
\end{tabular}




\begin{tabular}{|c|c|c|c|c|c|c|c|c|c|c|c|c|c|}
\hline 40 & 204600 & 0.01153 & 0.02405 & 0.01537 & 0.02789 & 0.01729 & 0.02981 & 0.02305 & 0.03557 & 0.03458 & 0.04710 & 0.04611 & 0.05863 \\
\hline 45 & 204300 & 0.01154 & 0.02406 & 0.01539 & 0.02791 & 0.01732 & 0.02983 & 0.02309 & 0.03561 & 0.03463 & 0.04715 & 0.04618 & 0.05869 \\
\hline 50 & 204000 & 01156 & .02408 & 0.01541 & 0.02793 & 0.01734 & 0.02986 & 0.02312 & 0.03564 & 0.03468 & 0.04720 & 0.04624 & 0.05876 \\
\hline 55 & 203700 & 01158 & 0.02410 & 0.01544 & 0.02796 & 0.01737 & 0.02989 & 0.02316 & 0.03567 & 0.03473 & 0.04725 & 0.04631 & 0.05883 \\
\hline 60 & 203400 & 01159 & 0.02411 & 0.01546 & 0.02798 & 0.01739 & 0.02991 & 0.02319 & 0.03571 & 0.03478 & 0.04730 & 0.04638 & 0.05890 \\
\hline 65 & 203100 & 01161 & 0.02413 & 0.01548 & 0.02800 & 0.01742 & 0.02994 & & 0.03574 & 0.03484 & 0.04736 & 0.04645 & 0.05897 \\
\hline 70 & 202800 & 01163 & 0.02415 & 0.01551 & 0.02802 & 0.01744 & 0.02996 & 0.02326 & 0.03578 & 0.03489 & 0.04741 & 0.04652 & 0.05904 \\
\hline 75 & 202500 & 01165 & 0.02417 & 0.01553 & 0.02805 & 0.01747 & 0.02999 & 0.02329 & 0.03581 & 0.03494 & 0.04746 & 0.04659 & 0.05910 \\
\hline 80 & 202200 & .01166 & 0.02418 & 0.01555 & 0.02807 & 0.01750 & 0.03001 & 0.02333 & 0.03585 & 0.03499 & 0.04751 & 0.04665 & 0.05917 \\
\hline 85 & 201900 & 01168 & 0.02420 & 0.01557 & 0.02809 & 0.01752 & 0.03004 & 0.02336 & 0.03588 & 0.03504 & 0.04756 & 0.04672 & 0.05924 \\
\hline 90 & 201600 & 01170 & 0.02422 & 0.01560 & 0.02812 & 0.01755 & 0.03007 & 0.02340 & 0.03592 & 0.03510 & 0.04761 & 0.04679 & 0.05931 \\
\hline 95 & 201300 & 01172 & 0.02424 & 0.01562 & 0.02814 & 01757 & 0.03009 & 0.02343 & 0.03595 & .03515 & 0.04767 & 04686 & 5938 \\
\hline 100 & 201000 & 01173 & 0.02425 & 0.01564 & 0.02816 & 0.01760 & 0.03012 & 0.02347 & 0.03599 & 0.03520 & 0.04772 & 0.04693 & 0.05945 \\
\hline 105 & 200700 & 01175 & 0.02427 & 0.01567 & 0.02819 & 0.01763 & 0.03015 & 0.02350 & 0.03602 & 0.03525 & 0.04777 & 0.04700 & 0.05952 \\
\hline 110 & 200400 & 01177 & 0.02429 & 0.01569 & 0.02821 & 0.01765 & 0.03017 & .02354 & 0.03606 & 0.03531 & 0.04782 & 0.04707 & 0.05959 \\
\hline 115 & 200100 & 01179 & 0.02431 & 0.01571 & 0.02823 & 0.01768 & 0.03020 & 0.02357 & 0.03609 & 0.03536 & 0.04788 & 0.04714 & 0.05966 \\
\hline 120 & 199800 & 01180 & 0.02432 & 0.01574 & 0.02826 & 0.01771 & 0.03022 & 0.02361 & 0.03613 & .03541 & 0.04793 & .04722 & 0.05973 \\
\hline 125 & 199500 & 01182 & 0.02434 & 0.01576 & 0.02828 & 0.01773 & 0.03025 & 0.02364 & 0.03616 & 0.03546 & 0.04798 & 0.04729 & 0.05981 \\
\hline 130 & 199200 & 1184 & 0.02436 & 0.01579 & 0.02831 & 0.01776 & 0.03028 & 0.02368 & 0.03620 & 0.03552 & 0.04804 & 0.04736 & 0.05988 \\
\hline 135 & 198900 & 01186 & 0.02438 & 0.01581 & 0.02833 & 0.01779 & 0.03031 & 02371 & 0.03623 & 0.03557 & 4809 & 0.04743 & 0.05995 \\
\hline 140 & 198600 & 01188 & 0.02439 & 0.01583 & 0.02835 & 0.01781 & 0.03033 & 0.02375 & 0.03627 & 0.03563 & 0.04814 & 0.04750 & 0.06002 \\
\hline 145 & 198300 & D1189 & 0.02441 & 0.01586 & 0.02838 & 0.01784 & 0.03036 & 0.02379 & 0.03631 & 0.03568 & 0.04820 & 0.04757 & 0.06009 \\
\hline 150 & 198000 & 01191 & 0.02443 & 0.01588 & 0.02840 & 0.01787 & 0.03039 & 0.02382 & 0.03634 & 0.03573 & 0.04825 & 04764 & 0.06016 \\
\hline 155 & 197700 & 01193 & 0.02445 & 0.01591 & 0.02842 & 0.01789 & 0.03041 & 0.02386 & 0.03638 & 0.03579 & 0.04831 & .04772 & 0.06024 \\
\hline 160 & 197400 & 01195 & 0.02447 & 0.01593 & 0.02845 & 0.01792 & 0.03044 & 0.02389 & 0.03641 & 0.03584 & 0.04836 & 0.04779 & 0.06031 \\
\hline 165 & 197100 & 01197 & 0.02448 & 0.01595 & 0.02847 & 0.01795 & 0.03047 & & & 0.03590 & & 0.04786 & 0.06038 \\
\hline 170 & 196800 & 01198 & 0.02450 & 0.01598 & 0.02850 & 0.01798 & 0.03049 & 0.02397 & 0.03649 & 0.03595 & 0.04847 & 0.04793 & 0.06045 \\
\hline 175 & 196500 & 01200 & 0.02452 & 0.01600 & 0.02852 & 0.01800 & 0.03052 & 0.02400 & 0.03652 & 0.03601 & 0.04853 & 0.04801 & 0.06053 \\
\hline 180 & 196200 & 01202 & 0.02454 & 0.01603 & 0.02855 & 0.01803 & 0.03055 & 0.02404 & 0.03656 & 0.03606 & 0.04858 & 0.04808 & 0.06060 \\
\hline 185 & 195900 & 01204 & 0.02456 & 0.01605 & 0.02857 & 0.01806 & 0.03058 & 0.02408 & 0.03660 & 0.03612 & 0.04864 & 0.04816 & 0.06067 \\
\hline 190 & 195600 & 06 & 0.02458 & 0. & 0 & 99 & 3061 & & 63 & 17 & & 23 & 775 \\
\hline 195 & 195300 & 1208 & 59 & 0.01610 & & 0.01 & & & & 23 & & & 082 \\
\hline 200 & 195000 & D1209 & 0.02461 & 0.01613 & 0.02865 & 0.01814 & 0.03066 & 419 & 0.03671 & 0.03628 & 880 & 838 & 0.06090 \\
\hline 205 & 194700 & 01211 & 0.02463 & 0.01615 & 0.02867 & 0.01817 & 0.03069 & 0.02423 & 0.03675 & 0.03634 & 0.04886 & 0.04845 & 0.06097 \\
\hline 210 & 194400 & 01213 & 0.02465 & 0.01618 & 0.02869 & 0.01820 & 0.03072 & 0.02426 & 0.03678 & 0.03640 & 0.04891 & 0.04853 & 0.06105 \\
\hline 215 & 194100 & 01215 & 0.02467 & 0.01620 & 0.02872 & 0.01823 & 0.03074 & .02430 & 0.03682 & 0.03645 & 0.04897 & 0.04860 & 0.06112 \\
\hline 220 & 193800 & 1217 & & & & & 077 & & & 651 & 03 & 368 & 120 \\
\hline 225 & 193500 & D1219 & 0.02471 & 0.01625 & 0.02877 & 0.01828 & 080 & & 0.0 & 56 & 08 & 375 & 0.06127 \\
\hline 230 & 193200 & 1221 & 0.02473 & 0.01628 & 0.02880 & .01831 & 0.03083 & 41 & 693 & 662 & 914 & 383 & 0.06135 \\
\hline 235 & 192900 & 1223 & 0.02475 & 0.01630 & 0.02882 & 0.01834 & 0.03086 & .02445 & 0.03697 & 03668 & 0.04920 & 04890 & 0.06142 \\
\hline 240 & 192600 & 01225 & 0.02476 & 0.01633 & 0.02885 & 0.01837 & 0.03089 & 0.02449 & 0.03701 & 0.03674 & 0.04925 & 0.04898 & 0.06150 \\
\hline 245 & 192300 & 0.01226 & 0.02478 & 0.01635 & 0.02887 & 0.01840 & 0.03092 & 0.02453 & 0.03705 & 0.03679 & 0.04931 & 0.04906 & 0.06158 \\
\hline 250 & 192000 & D1228 & 0.02480 & 0.01638 & 0.02890 & 0.01842 & 0.03094 & 0.02457 & 0.03709 & 0.03685 & 937 & 0.04913 & 0.06165 \\
\hline 255 & 700 & 1230 & 0.02482 & 0.01640 & & 1845 & 097 & & 712 & 691 & & 921 & 0.06173 \\
\hline 260 & 191400 & 01232 & 0.02484 & 0.01643 & 0.02895 & 0.01848 & 0.03100 & 0.02464 & 0.03716 & 0.03697 & 948 & 0.04929 & 0.06181 \\
\hline 265 & 191100 & 1234 & 0.02486 & 0.01645 & 0.02897 & 0.01851 & 0.03103 & 0.02468 & 0.03720 & 0.03702 & 0.04954 & .04936 & 0.06188 \\
\hline 270 & 190800 & 1236 & 0.02488 & 0.01648 & 0.02900 & 0.01854 & 0.03106 & 02472 & 0.03724 & 0.03708 & 0.04960 & .04944 & 0.06196 \\
\hline 275 & 190500 & 01238 & 0.02490 & 0.01651 & 0.02903 & 0.01857 & 0.03109 & 0.02476 & 0.03728 & 0.03714 & 966 & 04952 & 0.06204 \\
\hline 280 & 190200 & 1240 & 0.02492 & 0.01653 & 0.02905 & 0.01860 & 0.03112 & 0.02480 & 0.03732 & 0.03720 & 0.04972 & 0.04960 & 0.06212 \\
\hline 285 & 189900 & 01242 & 0.02494 & 0.01656 & 0.02908 & 0.01863 & 0.03115 & 0.02484 & 0.03736 & 0.03726 & 978 & 0.04968 & 0.06220 \\
\hline 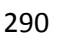 & 00 & 1244 & 96 & 0.01659 & 10 & 1800 & 118 & 888 & 740 & 3732 & 84 & 4976 & 06227 \\
\hline 295 & 189300 & 0.01246 & 98 & 0.01661 & 2913 & 0.01869 & 121 & 492 & 744 & 0.03738 & 989 & 0.04983 & 0.06235 \\
\hline 300 & 189000 & 0.01248 & 0.02500 & 0.01664 & 0.02916 & 0.01872 & 0.03124 & 0.02496 & 0.03748 & 0.03743 & 0.04995 & 0.04991 & 0.06243 \\
\hline
\end{tabular}




\begin{tabular}{|c|c|c|c|c|c|c|c|c|c|c|c|c|c|}
\hline \multirow{2}{*}{\multicolumn{2}{|c|}{$\begin{array}{r}\text { Specimen type: } \\
\text { Thickness } \mathrm{B}(\mathrm{mm})=\end{array}$}} & \multicolumn{2}{|c|}{ CVN } & \multicolumn{2}{|c|}{$3 / 4-5 S$} & \multicolumn{2}{|c|}{$2 / 3-S S$} & \multicolumn{2}{|c|}{$1 / 2$-SS } & \multicolumn{2}{|c|}{$1 / 3-S S$} & \multicolumn{2}{|c|}{ 1/4-SS } \\
\hline & & \multicolumn{2}{|c|}{10} & \multicolumn{2}{|c|}{7.5} & \multicolumn{2}{|c|}{6.67} & \multicolumn{2}{|c|}{5} & \multicolumn{2}{|c|}{3.33} & \multicolumn{2}{|c|}{2.5} \\
\hline & $\mathrm{nS}(\mathrm{mm})=$ & & & & & & & & & & & & \\
\hline & $\mathrm{h} W(\mathrm{~mm})=$ & 1 & & & & & & & & & & & \\
\hline Notch & th $\mathrm{a}(\mathrm{mm})=$ & & & & & & & & & & & & \\
\hline & $\mathrm{a} / \mathrm{W}=$ & 0 & & & & & & & & & & & \\
\hline & $f(a / W)=$ & 0.943 & 3584 & 0.94 & 3584 & 0.94 & 3584 & 0.94 & 3584 & 0.94 & 3584 & 0.94 & 3584 \\
\hline & & & & $3 / 4$ & SS & & -SS & & -SS & & -SS & & \\
\hline T & E & $C_{s}$ & $C_{\text {exp }}$ & $\mathrm{C}_{\mathrm{s}}$ & $C_{\text {exp }}$ & $\mathrm{C}_{\mathrm{s}}$ & $C_{\text {exp }}$ & $\mathrm{C}_{\mathrm{s}}$ & $C_{\text {exp }}$ & $\mathrm{C}_{\mathrm{s}}$ & $\mathrm{C}_{\text {exp }}$ & & $C_{\text {exp }}$ \\
\hline$\left({ }^{\circ} \mathrm{C}\right)$ & $\left(\mathrm{N} / \mathrm{mm}^{2}\right)$ & $(\mathrm{mm}$ & (kN) & $(\mathrm{mm}$ & (kN) & $(\mathrm{mm}$ & (kN) & $(\mathrm{mm}$ & (kN) & $(\mathrm{m}$ & (kN) & & \\
\hline-180 & 217800 & 0.01083 & 0.02306 & 0.01444 & 0.02667 & 0.01624 & 0.02848 & 0.02166 & 0.03389 & 0.03248 & 0.04472 & 0.04331 & 0.05555 \\
\hline-175 & 217500 & 0.01084 & 0.02308 & 0.01446 & 0.02669 & 0.01626 & 0.02850 & 02169 & 0.03392 & .03253 & 0.04476 & 1.04337 & 0.05561 \\
\hline-170 & 217200 & 0.01086 & 0.02309 & 0.01448 & 0.02671 & 0.01629 & 0.02852 & 0.02172 & 0.03395 & 0.03257 & 0.04481 & 0.04343 & 0.05567 \\
\hline-165 & 216900 & 0.01087 & 0.02311 & 0.01450 & 0.02673 & 0.01631 & 0.02854 & 0.02175 & 0.03398 & 0.03262 & 0.04485 & 0.04349 & 0.05573 \\
\hline-160 & 216600 & 0.01089 & 0.02312 & 0.01452 & 0.02675 & 0.01633 & 0.02857 & 0.02178 & 0.03401 & .03266 & 0.04490 & .04355 & 0.05579 \\
\hline-155 & 216300 & 0.01090 & 0.02314 & 0.01454 & 0.02677 & 0.01636 & 0.02859 & 0.02181 & 0.03404 & 0.03271 & 0.04494 & 0.04361 & 0.05585 \\
\hline-150 & 000 & 0.01092 & 0.02315 & 0.01456 & 0.02679 & 0.01638 & 0.02861 & 0.02184 & 0.03407 & 0.03276 & 0.04499 & 0.04367 & 0.05591 \\
\hline-145 & 5700 & 0.01093 & 0.02317 & 0.01458 & 0.02681 & 0.01640 & 0.02863 & 0.02187 & 03410 & 0.03280 & 0.0 & 0.04373 & 0.05597 \\
\hline-140 & 5400 & 0.01095 & 0.02318 & 0.01460 & 0.02683 & 0.01642 & 0.02866 & 0.02190 & .03413 & .03285 & 0.04508 & 0.04380 & 0.05603 \\
\hline-135 & 215100 & 0.01096 & 0.02320 & 0.01462 & 0.02685 & 0.01645 & 0.02868 & 0.02193 & 0.03416 & .03289 & 0.04513 & .04386 & 0.05609 \\
\hline-130 & 214800 & 0.01098 & 0.02321 & 0.01464 & 0.02687 & 0.01647 & 0.02870 & 0.02196 & 03419 & 0.03294 & 0.04517 & 0.04392 & 0.05615 \\
\hline-125 & 21 & 0.01099 & 0.0 & 0.01466 & 0.02689 & 0.01649 & 0.02873 & 0.02199 & 22 & 98 & & 98 & 0.05621 \\
\hline-120 & 200 & 0.01101 & 0.02324 & 0.01468 & 0.02691 & 0.01652 & 0.02875 & 0.02202 & 03425 & 0.03303 & 0.0 & .04404 & 0.05627 \\
\hline-115 & 3900 & 0.01103 & 0.02326 & 0.01470 & 0.02693 & 0.01654 & 0.02877 & 0.02205 & 03428 & 0.03308 & 31 & .04410 & 0.05634 \\
\hline-110 & 600 & 0.01104 & 0.02327 & 0.01472 & 0.02695 & 0.01656 & 0.02880 & 0.02208 & 0.03432 & .03312 & 36 & 16 & 0.05640 \\
\hline-105 & 2 & 0.01106 & 0.02329 & 0.01474 & 0.02698 & 0.01659 & 32 & 0.02 & 35 & 17 & 40 & 123 & 0.05646 \\
\hline-100 & & 1107 & & 0.01 & 0.02700 & 0.01 & 0.0 & 0.02 & & 0.0 & & & 0.0 \\
\hline-95 & 700 & 0.01109 & 2 & 0.01478 & 0.02702 & 0.01663 & 0.02887 & 0.02218 & 41 & 0.03326 & 50 & 0.0 & 0.05658 \\
\hline-90 & 400 & 0.01110 & 0.02334 & 0.01480 & 0.02704 & 0.01666 & 0.02889 & 0.02221 & .03444 & 0.03331 & 54 & 0.0 & 0.05665 \\
\hline-85 & & 1112 & 0.02335 & 0.01483 & 0.02706 & 0.01668 & 91 & 02224 & 47 & .03336 & & & 0.05671 \\
\hline-80 & 80 & 0.01114 & 0.02337 & 0.01485 & 0.02708 & 0.01670 & 0.02894 & 0.02227 & 50 & 0.03 & 34 & 54 & 0.05677 \\
\hline-75 & & 5 & & 0.01 & 0 & 0. & & 0.0 & 53 & & & & 0.0 \\
\hline-70 & & 117 & 0 & 39 & 0.02712 & 75 & 98 & 33 & 157 & 0.0 & 73 & $0 . c$ & 0.05690 \\
\hline-65 & 00 & 1118 & 0.02342 & 0.01491 & 0.02714 & 0.01677 & 0.02901 & 0.02237 & 460 & 0.03355 & 78 & .04473 & 0.05696 \\
\hline-60 & & 1120 & & & 0.02716 & 0.01680 & & 02240 & & & & 79 & 0.05703 \\
\hline-55 & & 0.01121 & 0.02345 & 0.014 & & 0.01 & 05 & & & 0.0 & & 186 & 0.05709 \\
\hline-50 & & & & & & & & & & & & & 0.05716 \\
\hline-45 & & & & & & 0. & & & & & & & 0.0 \\
\hline-40 & 400 & 126 & 0 & 2 & 0.02 & 39 & 13 & 53 & 76 & 79 & 02 & 55 & 0.05728 \\
\hline-35 & 9100 & 1128 & 0.02351 & 01504 & 0.02727 & 0.01692 & 0.02915 & 0.02256 & 03479 & 0.03384 & 07 & .04512 & 0.05735 \\
\hline-30 & 800 & 0.01130 & 0.02353 & .01506 & 0.02729 & 0.01694 & 18 & 0.02259 & 3482 & 0.03389 & & 18 & 0.05741 \\
\hline-25 & 208500 & 0.01131 & & & & & & & & & & & 0.05748 \\
\hline-20 & & & & & & & & & & & & & \\
\hline-15 & & & & & & & & & & & & & \\
\hline-10 & 600 & 136 & 0.02 & 5 & 0.02 & 0.01704 & 27 & 02272 & 95 & 0.03408 & 31 & 44 & 0.05767 \\
\hline-5 & 300 & 1138 & 0.02361 & 01517 & 0.02740 & 0.01707 & 30 & 0.02275 & 99 & 0.03413 & & 51 & 0.05774 \\
\hline 0 & 207000 & 139 & 0.02363 & 19 & 0.02742 & 0.01709 & & 0.02279 & 02 & 0.03418 & & . 04557 & 0.05781 \\
\hline 5 & & & & & & & & & & & & & 787 \\
\hline 10 & & & & & & & & & & & & & \\
\hline 15 & & 44 & & & & 0.0 & & 0.02289 & & .03433 & & .04577 & 801 \\
\hline 20 & & 146 & 9 & 8 & $\overline{1}$ & 0.01719 & 12 & 0.02292 & & 38 & & 84 & \\
\hline 21 & 2 & 146 & 0. & 8 & 0.027 & 0.01719 & & 93 & & 39 & & & 809 \\
\hline 22 & 205680 & 0.01147 & 0.02370 & 0.01529 & 0.02752 & 0.01720 & 0.02943 & 0.02293 & 03517 & 0.03440 & 0.04663 & 0.04587 & 0.05810 \\
\hline 23 & 205620 & 1147 & 0.02370 & 0.01529 & & 0.01720 & & & & & & & \\
\hline 24 & 560 & 147 & & & & & & & & & & & \\
\hline 25 & & 148 & 1 & 30 & 4 & 01721 & & 295 & 19 & 3443 & & .04591 & .05814 \\
\hline 30 & 200 & 149 & 0.02373 & 0.01532 & 0.02756 & 0.01724 & 0.02947 & 0.02299 & 0.03522 & 0.03448 & 0.04671 & 0.04597 & 0.05821 \\
\hline 35 & 204900 & 0.01151 & 0.02374 & 0.01535 & 0.02758 & 0.01726 & 0.02950 & 0.02302 & 0.03525 & 0.03453 & 0.04676 & 0.04604 & 0.0582 \\
\hline
\end{tabular}




\begin{tabular}{|c|c|c|c|c|c|c|c|c|c|c|c|c|c|}
\hline 40 & 204600 & 0.01153 & 0.02376 & 0.01537 & 0.02760 & 0.01729 & 0.02952 & 0.02305 & 0.03529 & 0.03458 & 0.04681 & 0.04611 & 0.05834 \\
\hline 45 & 204300 & 0.01154 & 0.02378 & 0.01539 & 0.02763 & 0.01732 & 0.02955 & 0.02309 & 0.03532 & 0.03463 & 0.04686 & 0.04618 & 0.05841 \\
\hline 50 & 204000 & 01156 & .02379 & 0.01541 & 0.02765 & 0.01734 & 0.02957 & 0.02312 & 0.03535 & 0.03468 & 0.04692 & 0.04624 & 0.05848 \\
\hline 55 & 203700 & 01158 & 0.02381 & 0.01544 & 0.02767 & 0.01737 & 0.02960 & 0.02316 & 0.03539 & 0.03473 & 0.04697 & 0.04631 & 0.05854 \\
\hline 60 & 203400 & 01159 & 0.02383 & 0.01546 & 0.02769 & 0.01739 & 0.02963 & 0.02319 & 0.03542 & 0.03478 & 0.04702 & 0.04638 & 0.05861 \\
\hline 65 & 203100 & 01161 & 0.02385 & 0.01548 & 0.02772 & 0.01742 & 0.02965 & 22 & 0.03546 & 0.03484 & 0.04707 & 0.04645 & 0.05868 \\
\hline 70 & 202800 & 01163 & 0.02386 & 0.01551 & 0.02774 & 0.01744 & 0.02968 & 0.02326 & 0.03549 & 0.03489 & 0.04712 & 0.04652 & 0.05875 \\
\hline 75 & 202500 & 01165 & 0.02388 & 0.01553 & 0.02776 & 0.01747 & 0.02970 & 0.02329 & 0.03553 & 0.03494 & 0.04717 & 0.04659 & 0.05882 \\
\hline 80 & 202200 & .01166 & 0.02390 & 0.01555 & 0.02778 & 0.01750 & 0.02973 & 0.02333 & 0.03556 & 0.03499 & 0.04722 & 0.04665 & 0.05889 \\
\hline 85 & 201900 & 01168 & 0.02391 & 0.01557 & 0.02781 & 0.01752 & 0.02975 & 0.02336 & 0.03560 & 0.03504 & 0.04728 & 0.04672 & 0.05896 \\
\hline 90 & 201600 & 01170 & 0.02393 & 0.01560 & 0.02783 & 0.01755 & 0.02978 & 0.02340 & 0.03563 & 0.03510 & 0.04733 & 0.04679 & 0.05903 \\
\hline 95 & 201300 & 01172 & 0.02395 & 0.01562 & 0.02785 & 01757 & 0.02981 & 0.02343 & 0.03566 & .03515 & 0.04738 & 04686 & 0.05910 \\
\hline 100 & 201000 & 01173 & 0.02397 & 0.01564 & 0.02788 & 0.01760 & 0.02983 & 0.02347 & 0.03570 & 0.03520 & 0.04743 & 0.04693 & 0.05917 \\
\hline 105 & 200700 & 01175 & 0.02398 & 0.01567 & 0.02790 & 0.01763 & 0.02986 & 0.02350 & 0.03574 & 0.03525 & 0.04749 & 0.04700 & 0.05924 \\
\hline 110 & 200400 & 01177 & 0.02400 & 0.01569 & 0.02792 & 0.01765 & 0.02989 & .02354 & 0.03577 & 0.03531 & 0.04754 & 0.04707 & 0.05931 \\
\hline 115 & 200100 & 01179 & 0.02402 & 0.01571 & 0.02795 & 0.01768 & 0.02991 & 0.02357 & 0.03581 & 0.03536 & 0.04759 & 0.04714 & 0.05938 \\
\hline 120 & 199800 & 01180 & 0.02404 & 0.01574 & 0.02797 & 0.01771 & 0.02994 & 0.02361 & 0.03584 & 0.03541 & 0.04764 & .04722 & 0.05945 \\
\hline 125 & 199500 & 01182 & 0.02405 & 0.01576 & 0.02800 & 0.01773 & 0.02997 & 0.02364 & 0.03588 & 0.03546 & 0.04770 & .04729 & 0.05952 \\
\hline 130 & 199200 & 01184 & 0.02407 & 0.01579 & 0.02802 & 0.01776 & 0.02999 & 0.02368 & 0.03591 & 0.03552 & 0.04775 & 0.04736 & 0.05959 \\
\hline 135 & 198900 & 01186 & 0.02409 & 0.01581 & 0.02804 & 0.01779 & 0.03002 & .02371 & 0.03595 & 0.03557 & 0.04780 & 0.04743 & 0.05966 \\
\hline 140 & 198600 & 01188 & 0.02411 & 0.01583 & 0.02807 & 0.01781 & 0.03005 & 0.02375 & 0.03598 & 0.03563 & 0.04786 & 0.04750 & 0.05973 \\
\hline 145 & 198300 & D1189 & 0.02413 & 0.01586 & 0.02809 & 0.01784 & 0.03007 & 0.02379 & 0.03602 & 0.03568 & 0.04791 & 0.04757 & 0.05981 \\
\hline 150 & 198000 & 01191 & 0.02414 & 0.01588 & 0.02811 & 0.01787 & 0.03010 & 0.02382 & 0.03606 & 0.03573 & 0.04797 & 04764 & 0.05988 \\
\hline 155 & 197700 & 01193 & 0.02416 & 0.01591 & 0.02814 & 0.01789 & 0.03013 & 0.02386 & 0.03609 & 0.03579 & 0.04802 & .04772 & 0.05995 \\
\hline 160 & 197400 & 01195 & 0.02418 & 0.01593 & 0.02816 & 0.01792 & 0.03015 & 0.02389 & 0.03613 & 0.03584 & 0.04808 & 0.04779 & 0.06002 \\
\hline 165 & 197100 & 0.01197 & & 0.01595 & 0.02819 & 0.01795 & 0.03018 & & 0.03616 & 0.03590 & 0.04813 & 0.04786 & 0.06010 \\
\hline 170 & 196800 & 01198 & 0.02422 & 0.01598 & 0.02821 & 0.01798 & 0.03021 & 0.02397 & 0.03620 & 0.03595 & 0.04818 & 0.04793 & 0.06017 \\
\hline 175 & 196500 & 01200 & 0.02424 & 0.01600 & 0.02824 & 0.01800 & 0.03024 & 0.02400 & 0.03624 & 0.03601 & 0.04824 & 0.04801 & 0.06024 \\
\hline 180 & 196200 & 01202 & 0.02425 & 0.01603 & 0.02826 & 0.01803 & 0.03026 & 0.02404 & 0.03627 & 0.03606 & 0.04829 & 04808 & 0.06031 \\
\hline 185 & 195900 & 01204 & 0.02427 & 0.01605 & 0.02829 & 0.01806 & 0.03029 & 0.02408 & 0.03631 & 0.03612 & 0.04835 & 0.04816 & 0.06039 \\
\hline 190 & 1 & 16 & & 0. & 31 & 99 & 032 & & & 17 & & 23 & 046 \\
\hline 195 & 195300 & 1208 & 0. & 0.01610 & & 0.01 & & & & 23 & & & 054 \\
\hline 200 & 195000 & D1209 & 0.02433 & 0.01613 & 0.02836 & 0.01814 & 0.03037 & 19 & 0.03642 & 0.03628 & 0.04852 & 838 & 0.06061 \\
\hline 205 & 194700 & 01211 & 0.02435 & 0.01615 & 0.02838 & 0.01817 & 0.03040 & 0.02423 & 0.03646 & 0.03634 & 0.04857 & 0.04845 & 0.06069 \\
\hline 210 & 194400 & 01213 & 0.02436 & 0.01618 & 0.02841 & 0.01820 & 0.03043 & 0.02426 & 0.03650 & 0.03640 & 0.04863 & 0.04853 & 0.06076 \\
\hline 215 & 194100 & 01215 & 0.02438 & 0.01620 & 0.02843 & 0.01823 & 0.03046 & .02430 & 0.03653 & 0.03645 & 0.04868 & 0.04860 & 0.06083 \\
\hline 220 & 193800 & 1217 & & & & & & & 557 & 651 & 374 & 368 & 6091 \\
\hline 225 & 193500 & 01219 & 0.02442 & 0.01625 & 0.02848 & 0.01828 & 0.1 & & 0.0 & 656 & 380 & 375 & 0.06099 \\
\hline 230 & 193200 & 1221 & 4 & 0.01628 & 0.02851 & .01831 & 054 & 41 & 665 & 662 & 385 & 883 & 0.06106 \\
\hline 235 & 192900 & 01223 & 0.02446 & 0.01630 & 0.02853 & 0.01834 & 0.03057 & .02445 & 0.03669 & 03668 & 0.04891 & 04890 & 0.06114 \\
\hline 240 & 192600 & 01225 & 0.02448 & 0.01633 & 0.02856 & 0.01837 & 0.03060 & 0.02449 & 0.03672 & 0.03674 & 0.04897 & 0.04898 & 0.06121 \\
\hline 245 & 192300 & 0.01226 & 0.02450 & 0.01635 & 0.02859 & 0.01840 & 0.03063 & 0.02453 & 0.03676 & 0.03679 & 0.04903 & 0.04906 & 0.06129 \\
\hline 250 & 192000 & D1228 & 0.02452 & 0.01638 & 0.02861 & 0.01842 & 066 & 0.02457 & 0.03680 & 0.03685 & 908 & 0.04913 & 0.06137 \\
\hline 255 & 700 & 1230 & & 0.01640 & & 1845 & & & 584 & 691 & 14 & 921 & 0.06144 \\
\hline 260 & 191400 & 01232 & 0.02456 & 0.01643 & 0.02866 & 0.01848 & 0.03072 & 0.02464 & 0.03688 & 0.03697 & 0.04920 & 0.04929 & 0.06152 \\
\hline 265 & 191100 & 1234 & 0.02457 & 0.01645 & 0.02869 & 0.01851 & 0.03075 & 0.02468 & 0.03692 & 0.03702 & 0.04926 & .04936 & 0.06160 \\
\hline 270 & 190800 & 1236 & 0.02459 & 0.01648 & 0.02871 & 0.01854 & 0.03077 & 02472 & 0.03695 & 0.03708 & 0.04932 & .04944 & 0.06168 \\
\hline 275 & 190500 & 0.01238 & 0.02461 & 0.01651 & 0.02874 & 0.01857 & 0.03080 & 0.02476 & 0.03699 & 0.03714 & 0.04937 & 04952 & 0.06175 \\
\hline 280 & 190200 & 01240 & 0.02463 & 0.01653 & 0.02877 & 0.01860 & 0.03083 & 0.02480 & 0.03703 & 0.03720 & 0.04943 & 0.04960 & 0.06183 \\
\hline 285 & 189900 & 01242 & 0.02465 & 0.01656 & 0.02879 & 0.01863 & 0.03086 & 0.02484 & 0.03707 & 0.03726 & 949 & 0.04968 & 0.06191 \\
\hline 290 & 1 & 244 & 7 & 1659 & 32 & 1866 & 89 & 2488 & 111 & 3732 & 955 & $9 / 6$ & 5199 \\
\hline 295 & 189300 & 0.01246 & $0 . c$ & 0.01661 & 0. & 0.01869 & 3092 & 492 & 715 & 0.03738 & 61 & 0.04983 & 0.06207 \\
\hline 300 & 189000 & 0.01248 & 0.02471 & 0.01664 & 0.02887 & 0.01872 & 0.03095 & 0.02496 & 0.03719 & 0.03743 & 0.04967 & 0.04991 & 0.06215 \\
\hline
\end{tabular}

Experimental compliance values for NIST Charpy machines.xIsx - TO3 + JS1 
Machine compliance: $0.0098 \mathrm{~mm} / \mathrm{kN}$

\begin{tabular}{|c|c|c|c|c|c|c|c|c|c|c|c|c|c|}
\hline \multirow{8}{*}{\multicolumn{2}{|c|}{$\begin{aligned} \text { Specimen type: } & \\
\text { Thickness } \mathrm{B}(\mathrm{mm}) & = \\
\text { Span } \mathrm{S}(\mathrm{mm}) & = \\
\text { Width } \mathrm{W}(\mathrm{mm}) & = \\
\text { Notch depth } \mathrm{a}(\mathrm{mm}) & = \\
\mathrm{a} / \mathrm{W} & = \\
\mathrm{f}(\mathrm{a} / \mathrm{W}) & =\end{aligned}$}} & \multicolumn{2}{|c|}{ CVN } & \multicolumn{2}{|c|}{$3 / 4-S S$} & \multicolumn{2}{|c|}{$2 / 3-S S$} & \multicolumn{2}{|c|}{$1 / 2-S S$} & \multicolumn{2}{|c|}{$1 / 3-S S$} & \multicolumn{2}{|c|}{$1 / 4-S S$} \\
\hline & & \multicolumn{2}{|c|}{10} & \multicolumn{2}{|c|}{7.5} & \multicolumn{2}{|c|}{6.67} & \multicolumn{2}{|c|}{5} & \multicolumn{2}{|c|}{3.33} & \multicolumn{2}{|c|}{2.5} \\
\hline & & \multicolumn{2}{|c|}{40} & & & & & & & & & & \\
\hline & & 1 & & & & & & & & & & & \\
\hline & & 2 & & & & & & & & & & & \\
\hline & & 0 & & & & & & & & & & & \\
\hline & & 0.943 & 3584 & 0.94 & 3584 & 0.94 & 3584 & 0.94 & 3584 & 0.94 & 3584 & 0.94 & 3584 \\
\hline & & $\mathrm{Cl}$ & & $3 /$ & -SS & $2 / 3$ & -SS & & SS & & & & \\
\hline $\begin{array}{c}\mathrm{T} \\
\left({ }^{\circ} \mathrm{C}\right)\end{array}$ & $\begin{array}{c}E \\
\left(N / \mathrm{mm}^{2}\right)\end{array}$ & $\begin{array}{l}\mathrm{C}_{\mathrm{s}} \\
(\mathrm{mm}\end{array}$ & $\begin{array}{l}C_{\text {exp }} \\
(k N)\end{array}$ & $\begin{array}{l}\mathrm{C}_{\mathrm{s}} \\
(\mathrm{mn}\end{array}$ & $\begin{array}{l}C_{\text {exp }} \\
(k N)\end{array}$ & $\begin{array}{l}\mathrm{C}_{\mathrm{s}} \\
\quad(\mathrm{mm}\end{array}$ & $\begin{array}{l}C_{\text {exp }} \\
(k N)\end{array}$ & $\begin{array}{l}\mathrm{C}_{\mathrm{s}} \\
(\mathrm{mn}\end{array}$ & $\begin{array}{l}C_{\text {exp }} \\
(k N)\end{array}$ & $\begin{array}{l}\mathrm{C}_{\mathrm{s}} \\
(\mathrm{mn}\end{array}$ & $\begin{array}{l}C_{\text {exp }} \\
\text { (kN) }\end{array}$ & $\begin{array}{l}\mathrm{C}_{\mathrm{s}} \\
\quad(\mathrm{mn}\end{array}$ & $\begin{array}{l}C_{\text {exp }} \\
\text { (kN) }\end{array}$ \\
\hline-180 & 217800 & 0.01083 & 0.02062 & 0.01444 & 0.02423 & 0.01624 & 0.02604 & 0.02166 & 0.03145 & 0.03248 & 0.04228 & 0.04331 & 0.05311 \\
\hline-175 & 217500 & 0.01084 & 0.02064 & 0.01446 & 0.02425 & 0.01626 & 0.02606 & 0.02169 & 0.03148 & 0.03253 & 0.04233 & 0.04337 & 0.05317 \\
\hline-170 & 217200 & 0.01086 & 0.02065 & 0.01448 & 0.02427 & 0.01629 & 0.02608 & 0.02172 & 0.03151 & 0.03257 & 0.04237 & 0.04343 & 0.05323 \\
\hline-165 & 216900 & 0.01087 & 0.02067 & 0.01450 & 0.02429 & 0.01631 & 0.02611 & 0.02175 & 0.03154 & 0.03262 & 0.04242 & 0.04349 & 0.05329 \\
\hline-160 & 216600 & 0.01089 & 0.02068 & 0.01452 & 0.02431 & 0.01633 & 0.02613 & 0.02178 & 0.03157 & 0.03266 & 0.04246 & 0.04355 & 0.05335 \\
\hline-155 & 216300 & 0.01090 & 0.02070 & 0.01454 & 0.02433 & 0.01636 & 0.02615 & 0.02181 & 0.03160 & 0.03271 & 0.04251 & 0.04361 & 0.05341 \\
\hline-150 & 216000 & 0.01092 & 0.02072 & 0.01456 & 0.02435 & 0.01638 & 0.02617 & 0.02184 & 0.03163 & 0.03276 & 0.04255 & 0.04367 & 0.05347 \\
\hline-145 & 215700 & 0.01093 & 0.02073 & 0.01458 & 0.02437 & 0.01640 & 0.02620 & 0.02187 & 0.03166 & 0.03280 & 0.04260 & 0.04373 & 0.05353 \\
\hline-140 & 215400 & 0.01095 & 0.02075 & 0.01460 & 0.02440 & 0.01642 & 0.02622 & 0.02190 & 0.03169 & 0.03285 & 0.04264 & 0.04380 & 0.05359 \\
\hline-135 & 215100 & 0.01096 & 0.02076 & 0.01462 & 0.02442 & 0.01645 & 0.02624 & 0.02193 & 0.03173 & 0.03289 & 0.04269 & 0.04386 & 0.05365 \\
\hline-130 & 214800 & 0.01098 & 0.02078 & 0.01464 & 0.02444 & 0.01647 & 0.02627 & 0.02196 & 0.03176 & 0.03294 & 0.04274 & 0.04392 & 0.05371 \\
\hline-125 & 214500 & 0.01099 & 0.02079 & 0.01466 & 0.02446 & 0.01649 & 0.02629 & 0.02199 & 0.03179 & 0.03298 & 0.04278 & 0.04398 & 0.05378 \\
\hline-120 & 214200 & 0.01101 & 0.02081 & 0.01468 & 0.02448 & 0.01652 & 0.02631 & 0.02202 & 0.03182 & 0.03303 & 0.04283 & 0.04404 & 0.05384 \\
\hline-115 & 213900 & 0.01103 & 0.02082 & 0.01470 & 0.02450 & 0.01654 & 0.02634 & 0.02205 & 0.03185 & 0.03308 & 0.04287 & 0.04410 & 0.05390 \\
\hline-110 & 213600 & 0.01104 & 0.02084 & 0.01472 & 0.02452 & 0.01656 & 0.02636 & 0.02208 & 0.03188 & 0.03312 & 0.04292 & 0.04416 & 0.05396 \\
\hline-105 & 213300 & 0.01106 & 0.02085 & 0.01474 & 0.02454 & 0.01659 & 0.02638 & 0.02211 & 0.03191 & 0.03317 & 0.04297 & 0.04423 & 0.05402 \\
\hline-100 & 213000 & 0.01107 & 0.02087 & 0.01476 & 0.02456 & 0.01661 & 0.02641 & 0.02214 & 0.03194 & 0.03322 & 0.04301 & 0.04429 & 0.05409 \\
\hline-95 & 212700 & 0.01109 & 0.02088 & 0.01478 & 0.02458 & 0.01663 & 0.02643 & 0.02218 & 0.03197 & 0.03326 & 0.04306 & 0.04435 & 0.05415 \\
\hline-90 & 212400 & 0.01110 & 0.02090 & 0.01480 & 0.02460 & 0.01666 & 0.02645 & 0.02221 & 0.03200 & 0.03331 & 0.04311 & 0.04441 & 0.05421 \\
\hline-85 & 212100 & 0.01112 & 0.02092 & 0.01483 & 0.02462 & 0.01668 & 0.02648 & 0.02224 & 0.03204 & 0.03336 & 0.04315 & 0.04448 & 0.05427 \\
\hline-80 & 211800 & 0.01114 & 0.02093 & 0.01485 & 0.02464 & 0.01670 & 0.02650 & 0.02227 & 0.03207 & 0.03341 & 0.04320 & 0.04454 & 0.05434 \\
\hline-75 & 211500 & 0.01115 & 0.02095 & 0.01487 & 0.02466 & 0.01673 & 0.02652 & 0.02230 & 0.03210 & 0.03345 & 0.04325 & 0.04460 & 0.05440 \\
\hline-70 & 211200 & 0.01117 & 0.02096 & 0.01489 & 0.02469 & 0.01675 & 0.02655 & 0.02233 & 0.03213 & 0.03350 & 0.04330 & 0.04467 & 0.05446 \\
\hline-65 & 210900 & 0.01118 & 0.02098 & 0.01491 & 0.02471 & 0.01677 & 0.02657 & 0.02237 & 0.03216 & 0.03355 & 0.04334 & 0.04473 & 0.05453 \\
\hline-60 & 210600 & 0.01120 & 0.02100 & 0.01493 & 0.02473 & 0.01680 & 0.02659 & 0.02240 & 0.03219 & 0.03360 & 0.04339 & 0.04479 & 0.05459 \\
\hline-55 & 210300 & 0.01121 & 0.02101 & 0.01495 & 0.02475 & 0.01682 & 0.02662 & 0.02243 & 0.03223 & 0.03364 & 0.04344 & 0.04486 & 0.05465 \\
\hline-50 & 210000 & 0.01123 & 0.02103 & 0.01497 & 0.02477 & 0.01685 & 0.02664 & 0.02246 & 0.03226 & 0.03369 & 0.04349 & 0.04492 & 0.05472 \\
\hline-45 & 209700 & 0.01125 & 0.02104 & 0.01500 & 0.02479 & 0.01687 & 0.02667 & 0.02249 & 0.03229 & 0.03374 & 0.04354 & 0.04499 & 0.05478 \\
\hline-40 & 209400 & 0.01126 & 0.02106 & 0.01502 & 0.02481 & 0.01689 & 0.02669 & 0.02253 & 0.03232 & 0.03379 & 0.04358 & 0.04505 & 0.05485 \\
\hline-35 & 209100 & 0.01128 & 0.02108 & 0.01504 & 0.02484 & 0.01692 & 0.02671 & 0.02256 & 0.03235 & 0.03384 & 0.04363 & 0.04512 & 0.05491 \\
\hline-30 & 208800 & 0.01130 & 0.02109 & 0.01506 & 0.02486 & 0.01694 & 0.02674 & 0.02259 & 0.03239 & 0.03389 & 0.04368 & 0.04518 & 0.05498 \\
\hline-25 & 208500 & 0.01131 & 0.02111 & 0.01508 & 0.02488 & 0.01697 & 0.02676 & 0.02262 & 0.03242 & 0.03393 & 0.04373 & 0.04525 & 0.05504 \\
\hline-20 & 208200 & 0.01133 & 0.02112 & 0.01510 & 0.02490 & 0.01699 & 0.02679 & 0.02266 & 0.03245 & 0.03398 & 0.04378 & 0.04531 & 0.05511 \\
\hline-15 & 207900 & 0.01134 & 0.02114 & 0.01513 & 0.02492 & 0.01702 & 0.02681 & 0.02269 & 0.03248 & 0.03403 & 0.04383 & 0.04538 & 0.05517 \\
\hline-10 & 207600 & 0.01136 & 0.02116 & 0.01515 & 0.02494 & 0.01704 & 0.02684 & 0.02272 & 0.03252 & 0.03408 & 0.04388 & 0.04544 & 0.05524 \\
\hline-5 & 207300 & 0.01138 & 0.02117 & 0.01517 & 0.02497 & 0.01707 & 0.02686 & 0.02275 & 0.03255 & 0.03413 & 0.04393 & 0.04551 & 0.05530 \\
\hline 0 & 207000 & 0.01139 & 0.02119 & 0.01519 & 0.02499 & 0.01709 & 0.02689 & 0.02279 & 0.03258 & 0.03418 & 0.04398 & 0.04557 & 0.05537 \\
\hline 5 & 206700 & 0.01141 & 0.02121 & 0.01521 & 0.02501 & 0.01711 & 0.02691 & 0.02282 & 0.03262 & 0.03423 & 0.04403 & 0.04564 & 0.05544 \\
\hline 10 & 206400 & 0.01143 & 0.02122 & 0.01524 & 0.02503 & 0.01714 & 0.02694 & 0.02285 & 0.03265 & 0.03428 & 0.04408 & 0.04571 & 0.05550 \\
\hline 15 & 206100 & 0.01144 & 0.02124 & 0.01526 & 0.02505 & 0.01716 & 0.02696 & 0.02289 & 0.03268 & 0.03433 & 0.04413 & 0.04577 & 0.05557 \\
\hline 20 & 205800 & 0.01146 & 0.02126 & 0.01528 & 0.02508 & 0.01719 & 0.02699 & 0.02292 & 0.03272 & 0.03438 & 0.04418 & 0.04584 & 0.05564 \\
\hline 21 & 205740 & 0.01146 & 0.02126 & 0.01528 & 0.02508 & 0.01719 & 0.02699 & 0.02293 & 0.03272 & 0.03439 & 0.04419 & 0.04585 & 0.05565 \\
\hline 22 & 205680 & 0.01147 & 0.02126 & 0.01529 & 0.02509 & 0.01720 & 0.02700 & 0.02293 & 0.03273 & 0.03440 & 0.04420 & 0.04587 & 0.05566 \\
\hline 23 & 205620 & 0.01147 & 0.02127 & 0.01529 & 0.02509 & 0.01720 & 0.02700 & 0.02294 & 0.03274 & 0.03441 & 0.04421 & 0.04588 & 0.05568 \\
\hline 24 & 205560 & 0.01147 & 0.02127 & 0.01530 & 0.02509 & 0.01721 & 0.02701 & 0.02295 & 0.03274 & 0.03442 & 0.04422 & 0.04589 & 0.05569 \\
\hline 25 & 205500 & 0.01148 & 0.02127 & 0.01530 & 0.02510 & 0.01721 & 0.02701 & 0.02295 & 0.03275 & 0.03443 & 0.04423 & 0.04591 & 0.05570 \\
\hline 30 & 205200 & 0.01149 & 0.02129 & 0.01532 & 0.02512 & 0.01724 & 0.02704 & 0.02299 & 0.03278 & 0.03448 & 0.04428 & 0.04597 & 0.05577 \\
\hline 35 & 204900 & 0.01151 & 0.02131 & 0.01535 & 0.02514 & 0.01726 & 0.02706 & 0.02302 & 0.03282 & 0.03453 & 0.04433 & 0.04604 & 0.05584 \\
\hline
\end{tabular}




\begin{tabular}{|c|c|c|c|c|c|c|c|c|c|c|c|c|c|}
\hline 40 & 204600 & 0.01153 & 0.02132 & 0.01537 & 0.02517 & 0.01729 & 0.02709 & 0.02305 & 0.03285 & 0.03458 & 0.04438 & 04611 & 0.05590 \\
\hline 45 & 204300 & 0.01154 & 0.02134 & 0.01539 & 0.02519 & 0.01732 & 0.02711 & 0.02309 & 0.03288 & 0.03463 & 0.04443 & 0.04618 & 0.05597 \\
\hline 50 & 204000 & 01156 & .02136 & 0.01541 & 0.02521 & 0.01734 & 0.02714 & 0.02312 & 0.03292 & 0.03468 & 0.04448 & 0.04624 & 0.05604 \\
\hline 55 & 203700 & 01158 & 0.02137 & 0.01544 & 0.02523 & 0.01737 & 0.02716 & 0.02316 & 0.03295 & 0.03473 & 0.04453 & 0.04631 & 0.05611 \\
\hline 60 & 203400 & 01159 & 0.02139 & 0.01546 & 0.02526 & 0.01739 & 0.02719 & 0.02319 & 0.03299 & 0.03478 & 0.04458 & 0.04638 & 0.05618 \\
\hline 65 & 203100 & 01161 & 0.02141 & 0.01548 & .02528 & 1742 & 2721 & & 0.03302 & 0.03484 & 0.04463 & 0.04645 & 0.05624 \\
\hline 70 & 202800 & 01163 & 0.02143 & 0.01551 & 0.02530 & 0.01744 & 0.02724 & 0.02326 & 0.03306 & 0.03489 & 0.04468 & 0.04652 & 0.05631 \\
\hline 75 & 202500 & 01165 & 0.02144 & 0.01553 & 0.02533 & 0.01747 & 0.02727 & 0.02329 & 0.03309 & 0.03494 & 0.04474 & 0.04659 & 0.05638 \\
\hline 80 & 202200 & .01166 & 0.02146 & 0.01555 & 0.02535 & 0.01750 & 0.02729 & 0.02333 & 0.03312 & 0.03499 & 0.04479 & 0.04665 & 0.05645 \\
\hline 85 & 201900 & 0.01168 & 0.02148 & 0.01557 & 0.02537 & 0.01752 & 0.02732 & 0.02336 & 0.03316 & 0.03504 & 0.04484 & 0.04672 & 0.05652 \\
\hline 90 & 201600 & 01170 & 0.02150 & 0.01560 & 0.02539 & 0.01755 & 0.02734 & 0.02340 & 0.03319 & 0.03510 & 0.04489 & 0.04679 & 0.05659 \\
\hline 95 & 201300 & 01172 & 0.02151 & 0.01562 & 0.02542 & 01757 & .02737 & 0.02343 & 0.03323 & 0.03515 & 0.04494 & 0.04686 & 0.05666 \\
\hline 100 & 201000 & 01173 & 0.02153 & 0.01564 & 0.02544 & 0.01760 & 0.02740 & 0.02347 & 0.03326 & 0.03520 & 0.04500 & 0.04693 & 0.05673 \\
\hline 105 & 200700 & 01175 & 0.02155 & 0.01567 & 0.02546 & 0.01763 & 0.02742 & 0.02350 & 0.03330 & 0.03525 & 0.04505 & 0.04700 & 0.05680 \\
\hline 110 & 200400 & 01177 & 0.02157 & 0.01569 & 0.02549 & 0.01765 & 0.02745 & 0.02354 & 0.03333 & 0.03531 & 0.04510 & 0.04707 & 0.05687 \\
\hline 115 & 200100 & 01179 & 0.02158 & 0.01571 & 0.02551 & 0.01768 & 0.02748 & 0.02357 & 0.03337 & 0.03536 & 0.04515 & 0.04714 & 0.05694 \\
\hline 120 & 199800 & 01180 & 0.02160 & 0.01574 & 0.02554 & .01771 & 0.02750 & 0.02361 & 0.03340 & 0.03541 & 0.04521 & 0.04722 & 0.05701 \\
\hline 125 & 199500 & 01182 & 0.02162 & 0.01576 & 0.02556 & 0.01773 & 0.02753 & 0.02364 & 0.03344 & 0.03546 & 0.04526 & 0.04729 & 0.05708 \\
\hline 130 & 199200 & 01184 & 0.02164 & 0.01579 & 0.02558 & 0.01776 & 0.02756 & 0.02368 & 0.03348 & 0.03552 & 0.04531 & 0.04736 & 0.05715 \\
\hline 135 & 198900 & 01186 & 0.02165 & 0.01581 & 0.02561 & 0.01779 & 0.02758 & 0.02371 & 0.03351 & 0.03557 & 0.04537 & 0.04743 & 0.05723 \\
\hline 140 & 198600 & 01188 & 0.02167 & 0.01583 & 0.02563 & 0.01781 & 0.02761 & 0.02375 & 0.03355 & 0.03563 & 0.04542 & 0.04750 & 0.05730 \\
\hline 145 & 198300 & 01189 & 0.02169 & 0.01586 & 0.02565 & 0.01784 & 0.02764 & 0.02379 & 0.03358 & 0.03568 & 0.04548 & 0.04757 & 0.05737 \\
\hline 150 & 198000 & 01191 & 0.02171 & 0.01588 & 0.02568 & 0.01787 & 0.02766 & 0.02382 & 0.03362 & 0.03573 & 0.04553 & 0.04764 & 0.05744 \\
\hline 155 & 197700 & 01193 & 0.02173 & 0.01591 & 0.02570 & 0.01789 & 0.02769 & 0.02386 & 0.03366 & 0.03579 & 0.04558 & 0.04772 & 0.05751 \\
\hline 160 & 197400 & 01195 & 0.02174 & 0.01593 & 0.02573 & 0.01792 & 0.02772 & 0.02389 & 0.03369 & 0.03584 & 0.04564 & 0.04779 & 0.05759 \\
\hline 165 & 197100 & 0.01197 & 0.02176 & 0.01595 & 0.02575 & 0.01795 & 0.02774 & & 0.03373 & 0.03590 & 69 & 0.04786 & 0.05766 \\
\hline 170 & 196800 & 01198 & 0.02178 & 0.01598 & 0.02577 & 0.01798 & 0.02777 & 0.02397 & 0.03376 & 0.03595 & 0.04575 & 0.04793 & 0.05773 \\
\hline 175 & 196500 & 01200 & 0.02180 & 0.01600 & 0.02580 & 0.01800 & 0.02780 & 0.02400 & 0.03380 & 0.03601 & 0.04580 & 0.04801 & 0.05780 \\
\hline 180 & 196200 & 01202 & 0.02182 & 0.01603 & 0.02582 & 0.01803 & 0.02783 & 0.02404 & 0.03384 & 0.03606 & 0.04586 & 0.04808 & 0.05788 \\
\hline 185 & 195900 & 01204 & 0.02184 & 0.01605 & 0.02585 & 0.01806 & 0.02785 & 0.02408 & 0.03387 & 0.03612 & 0.04591 & 0.04816 & 0.05795 \\
\hline 190 & 195 & 16 & 185 & 0.0 & 0. & 0. & 88 & & 91 & 17 & 97 & 23 & 303 \\
\hline 195 & 195300 & D1208 & & 0.01610 & $0 . c$ & 0.01 & & & & 23 & & & 5810 \\
\hline 200 & 195000 & 01209 & 0.02189 & 0.01613 & 0.02592 & 0.01814 & 0.02794 & 19 & 0.03399 & 0.03628 & 0.04608 & 0.04838 & 0.05817 \\
\hline 205 & 194700 & 01211 & 0.02191 & 0.01615 & 0.02595 & 0.01817 & 0.02797 & 0.02423 & 0.03402 & 0.03634 & 0.04614 & 0.04845 & 0.05825 \\
\hline 210 & 194400 & 01213 & 0.02193 & 0.01618 & 0.02597 & 0.01820 & 0.02799 & 0.02426 & 0.03406 & 0.03640 & 0.04619 & 0.04853 & 0.05832 \\
\hline 215 & 194100 & 01215 & 0.02195 & 0.01620 & 0.02600 & 0.01823 & 0.02802 & 0.02430 & 0.03410 & 0.03645 & 0.04625 & .04860 & 0.05840 \\
\hline 220 & 193800 & 1217 & 0.02 & & & 0.01 & & & & 651 & 630 & 368 & 5847 \\
\hline 225 & 193500 & 01219 & 0.02198 & 0.01625 & 0.02605 & 0.01828 & 0.0 & & 0.0 & 656 & 536 & 375 & 0.05855 \\
\hline 230 & 193200 & 1221 & 0.02200 & 0.01628 & 0.02607 & 01831 & 11 & 41 & 121 & 662 & 542 & 883 & 0.05862 \\
\hline 235 & 192900 & 01223 & 0.02202 & 0.01630 & 0.02610 & 0.01834 & 0.02814 & 0.02445 & 0.03425 & 03668 & 0.04647 & 04890 & 0.05870 \\
\hline 240 & 192600 & 01225 & 0.02204 & 0.01633 & 0.02612 & 0.01837 & 0.02816 & 0.02449 & 0.03429 & 0.03674 & 0.04653 & 0.04898 & 0.05878 \\
\hline 245 & 192300 & 01226 & 0.02206 & 0.01635 & 0.02615 & 0.01840 & 0.02819 & 0.02453 & 0.03432 & 0.03679 & 0.04659 & 0.04906 & 0.05885 \\
\hline 250 & 192000 & 01228 & 0.02208 & 0.01638 & 0.02617 & 0.01842 & 0.02822 & 0.02457 & 436 & 0.03685 & 0.04665 & 0.04913 & 0.05893 \\
\hline 255 & 700 & 1230 & 0.02210 & 0.01640 & 0.0 & 1845 & & & & 691 & 670 & 921 & 0.05901 \\
\hline 260 & 191400 & 01232 & 0.02212 & 0.01643 & 0.02623 & 0.01848 & 0.02828 & 0.02464 & 444 & 0.03697 & 0.04676 & 0.04929 & 0.05908 \\
\hline 265 & 191100 & 1234 & 0.02214 & 0.01645 & 0.02625 & 0.01851 & 0.02831 & 0.02468 & 0.03448 & 0.03702 & 0.04682 & 0.04936 & 0.05916 \\
\hline 270 & 190800 & 1236 & 0.02216 & 0.01648 & 0.02628 & 0.01854 & 0.02834 & 0.02472 & 0.03452 & 0.03708 & 0.04688 & 0.04944 & 0.05924 \\
\hline 275 & 190500 & 0.01238 & 0.02218 & 0.01651 & 0.02630 & 0.01857 & 0.02837 & 0.02476 & 0.03456 & 0.03714 & 0.04694 & 0.04952 & .05932 \\
\hline 280 & 190200 & 0.01240 & 0.02220 & 0.01653 & 0.02633 & 0.01860 & 0.02840 & 0.02480 & 0.03460 & 0.03720 & 0.04700 & 0.04960 & 0.05939 \\
\hline 285 & 189900 & 01242 & 0.02222 & 0.01656 & 0.02636 & 0.01863 & 0.02843 & 0.02484 & 0.03463 & 0.03726 & 0.04705 & 0.04968 & 0.05947 \\
\hline 29 & 1 & 244 & 24 & 0.01659 & 8 & 56 & & 88 & 67 & 3732 & 711 & 976 & .05955 \\
\hline 295 & 189300 & 0.01246 & 26 & 0.01661 & 641 & 0.01869 & 348 & 492 & 471 & 0.03738 & 717 & 0.04983 & 0.05963 \\
\hline 300 & 189000 & 0.01248 & 0.02227 & 0.01664 & 0.02643 & 0.01872 & 0.02851 & 0.02496 & 0.03475 & 0.03743 & 0.04723 & 0.04991 & 0.05971 \\
\hline
\end{tabular}




\begin{tabular}{|c|c|c|c|c|c|c|c|c|c|c|c|c|c|}
\hline \multirow{2}{*}{\multicolumn{2}{|c|}{$\begin{array}{r}\text { Specimen type: } \\
\text { Thickness } B(\mathrm{~mm})=\end{array}$}} & \multicolumn{2}{|c|}{ CVN } & \multicolumn{2}{|c|}{$3 / 4-S S$} & \multicolumn{2}{|c|}{$2 / 3-S S$} & \multicolumn{2}{|c|}{$1 / 2-S S$} & \multicolumn{2}{|c|}{$1 / 3-S S$} & \multicolumn{2}{|c|}{ 1/4-SS } \\
\hline & & \multicolumn{2}{|c|}{10} & \multicolumn{2}{|c|}{7.5} & \multicolumn{2}{|c|}{6.67} & \multicolumn{2}{|c|}{5} & \multicolumn{2}{|c|}{3.33} & \multicolumn{2}{|c|}{2.5} \\
\hline & $\mathrm{nS}(\mathrm{mm})=$ & & & & & & & & & & & & \\
\hline & $\mathrm{h} \mathrm{W}(\mathrm{mm})=$ & 1 & & & & & & & & & & & \\
\hline Notch & th $\mathrm{a}(\mathrm{mm})=$ & & & & & & & & & & & & \\
\hline & $\mathrm{a} / \mathrm{W}=$ & & & & & & & & & & & & \\
\hline & $f(a / W)=$ & 0.943 & 3584 & 0.94 & 3584 & 0.94 & 3584 & 0.94 & & 0.94 & 884 & & 3584 \\
\hline & & & & & SS & & SS & $1 / 2$ & & $1 / 3$ & & & \\
\hline $\mathrm{T}$ & $E$ & $\mathrm{C}_{\mathrm{s}}$ & $C_{\text {exp }}$ & $\mathrm{C}_{\mathrm{s}}$ & $C_{\text {exp }}$ & $\mathrm{C}_{\mathrm{s}}$ & $C_{\text {exp }}$ & $\mathrm{C}_{\mathrm{s}}$ & $C_{\text {exp }}$ & $\mathrm{C}_{\mathrm{s}}$ & $C_{\text {exp }}$ & & $C_{\text {exp }}$ \\
\hline$\left({ }^{\circ} \mathrm{C}\right)$ & $\left(\mathrm{N} / \mathrm{mm}^{2}\right)$ & $(\mathrm{mm}$ & (kN) & & (kN) & $(\mathrm{mm}$ & (kN) & $(\mathrm{mm}$ & kN) & $(\mathrm{mm}$ & N) & & \\
\hline-180 & 217800 & 0.01083 & 0.02 & 0.01444 & 0.02 & 1624 & 0.02 & 2166 & 0.0 & 3248 & 0.04175 & 04331 & 0.05258 \\
\hline-175 & 217500 & 0.01084 & 0.02011 & 0.01446 & 0.02373 & 0.01626 & 0.02553 & 0.02169 & 0.03 & 0.03253 & 80 & 0.04337 & 0.05264 \\
\hline-170 & 217200 & 0.01086 & 0.02013 & 0.01448 & 0.02375 & 0.01629 & 0.02556 & 0.02172 & 0.03098 & 0.03257 & 0.04184 & 0.04343 & 0.05270 \\
\hline-165 & 216900 & 0.01087 & 0.02014 & 0.01450 & 0.02377 & 0.01631 & 0.02558 & 0.02175 & 0.03101 & 0.03262 & 0.04189 & 0.04349 & 0.05276 \\
\hline-160 & 216600 & 0.01089 & 0.02016 & 0.01452 & 0.02379 & 0.01633 & 0.02560 & 0.02178 & 0.03104 & 0.03266 & 0.04193 & 0.04355 & 0.05282 \\
\hline-155 & 216300 & 0.01090 & 0.02017 & 0.01454 & 0.02381 & 0.01636 & 0.02562 & 0.02181 & 0.03108 & 0.03271 & 0.04198 & 0.04361 & 0.05288 \\
\hline-150 & 000 & 0.01092 & 0.02019 & 0.01456 & 0.02383 & 0.01638 & 0.02565 & 0.02184 & 11 & 0.03276 & 02 & 0.04367 & 0.05294 \\
\hline-145 & 700 & 0.01093 & 0.02020 & 0.01458 & 0.02385 & 0.01640 & 0.02567 & 0.02187 & 03114 & .03280 & .04207 & 0.04373 & 0.05300 \\
\hline-140 & 5400 & 0.01095 & 0.02022 & 0.01460 & 0.02387 & 0.01642 & 0.02569 & 0.02190 & 03117 & .03285 & .04212 & .04380 & 0.05306 \\
\hline-135 & 215100 & 0.01096 & 0.02023 & 0.01462 & 0.02389 & 0.01645 & 0.02571 & 0.02193 & 0.03120 & 03289 & 0.04216 & 0.04386 & 0.05313 \\
\hline-130 & 214800 & 0.01098 & 0.02025 & 0.01464 & 0.02391 & 0.01647 & 0.02574 & 0.02196 & 0.03123 & 0.03294 & 0.04221 & 0.04392 & 0.05319 \\
\hline-125 & 00 & 0.01099 & 0.02026 & 0.01466 & 0.02393 & 0.01649 & 0.02576 & 0.02199 & & 03298 & 25 & & 0.05325 \\
\hline-120 & 200 & 0.01101 & 0.02028 & 0.01468 & 0.02395 & 0.01652 & 0.02578 & 0.02202 & 29 & .03303 & 30 & 0.0 & 0.05331 \\
\hline-115 & 3900 & 0.01103 & 0.02029 & 0.01470 & 0.02397 & 0.01654 & 0.02581 & 0.02205 & 03132 & .03308 & 35 & 0.04410 & 0.05337 \\
\hline-110 & 3600 & 0.01104 & 0.02031 & 0.01472 & 0.02399 & 0.01656 & 0.02583 & 0.02208 & 35 & .03312 & 39 & 0.04416 & 0.05343 \\
\hline-105 & 213300 & 0.01106 & 0.02033 & 0.01474 & 0.02401 & 0.01659 & 0.02585 & 0.02211 & 0.03138 & .03317 & 0.0 & 0.04423 & 0.05350 \\
\hline-100 & 213000 & 1107 & 0.02034 & 0.01476 & 0.02 & 0.01 & 0.0 & 0.02 & & 0.0 & & 0.0 & 0.0 \\
\hline-95 & 00 & 1109 & 0.02036 & 0.01478 & 0.02405 & 0.01663 & 0.0 & 0.02218 & 44 & 26 & 53 & 0.0 & 0.05362 \\
\hline-90 & 400 & 0.01110 & 0.02037 & 0.01480 & 0.02407 & 0.01666 & 0.02592 & 0.02221 & 48 & .03331 & 58 & 441 & 0.05368 \\
\hline-85 & & 1112 & & .01483 & 0.02409 & 0.01668 & & 24 & & & & & 0.05375 \\
\hline-80 & 2 & 0.01114 & 0.02040 & 0.01485 & 0.02 & 0.01 & 0.02 & 0.02227 & 54 & 41 & 67 & 54 & 0.05381 \\
\hline-75 & 50 & 0.01115 & 0.02042 & 0.01487 & 0.02 & 0.01673 & & 0.02230 & & 45 & & & 0.0 \\
\hline-70 & & 17 & 0. & 0.01 & 0.0 & 0.01 & 02 & 33 & & & & & \\
\hline-65 & 900 & 1118 & 0.02045 & 0.01491 & 0.02418 & 0.01677 & 0.0 & 0.02237 & 63 & 355 & 82 & 73 & 0.05400 \\
\hline-60 & 500 & 1120 & 047 & 193 & 0.02420 & 0.01680 & 0.02607 & 02240 & & 360 & & & 0.05406 \\
\hline-55 & 300 & 0.01121 & 0.02048 & 0.01495 & 0.02422 & 0.01682 & 0.02609 & 0.02243 & & .03364 & & 0.04486 & 0.05413 \\
\hline-50 & م000 & 0.01123 & 0.02050 & 0.01497 & 0.02424 & 0.01685 & & & & & & 0.04 & 0.05419 \\
\hline-45 & & & & 0.0 & 0.0 & 0.0 & & & & & & & \\
\hline-40 & 100 & 26 & 0.020 & 2 & 0.02 & 39 & 6 & 53 & & & & 55 & 32 \\
\hline-35 & 100 & 1128 & 0.02055 & 01504 & 0.02431 & 0.01692 & 0.02619 & 0.02256 & 83 & 03384 & 10 & 12 & 0.05438 \\
\hline-30 & 800 & 0.01130 & 0.02056 & 0.01506 & 0.02433 & 0.01694 & 0.02621 & 0.02259 & & 03389 & & .04518 & 0.05445 \\
\hline-25 & 208500 & 0.01131 & 0.02058 & & & & & & & & & & 0.05451 \\
\hline-20 & & & & & & & & & & & & & \\
\hline-15 & & & & & & & & & & & & & \\
\hline-10 & 500 & 136 & 0.0 & 5 & 0.02 & 0.01704 & 31 & 0.02272 & & 03408 & & 0.0 & 471 \\
\hline-5 & 30 & & & & 0.02444 & 0.01707 & 0.02633 & 02275 & & 03413 & & 51 & 0.05478 \\
\hline 0 & 207000 & 0.01139 & 0.02066 & 0.01519 & 0.02446 & 0.01709 & 0.02636 & 0.02279 & 0.03205 & .03418 & & . 04557 & 0.05484 \\
\hline 5 & 206700 & 141 & & 0.01521 & 0.02 & & & & & & & 0.04564 & 0.05491 \\
\hline 10 & & & & & & & & & & & & & \\
\hline 15 & 10 & 44 & & 6 & & 0.01 & & 0.02289 & & 433 & & .04577 & 0.05504 \\
\hline 20 & & & & 1528 & 0.024 & 0.01719 & 02646 & 02292 & & & & 84 & .05511 \\
\hline 21 & 205740 & 1146 & 0.02073 & 0.01528 & 0.02455 & 0.01719 & 0.02646 & 0.02293 & & 03439 & & 1.04585 & 0.05512 \\
\hline 22 & 205680 & 0.01147 & 0.02073 & 0.01529 & 0.02456 & 0.01720 & 0.02647 & 0.02293 & 0.03220 & 0.03440 & 0.04367 & 0.04587 & 0.05513 \\
\hline 23 & 205620 & 1147 & 0.02074 & 0.01529 & 0.024 & 0.01720 & 0.02647 & & & & & & \\
\hline 24 & 560 & & & & & & & & & & & & \\
\hline 25 & & 148 & & & & & & 295 & & 443 & & 591 & 0.05517 \\
\hline 30 & 200 & 0.01149 & 0.02076 & 0.01532 & 0.02459 & 0.01724 & 0.02651 & 0.02299 & 0.03225 & 0.03448 & 0.04375 & 0.04597 & 0.05524 \\
\hline 35 & 204900 & 0.01151 & 0.02078 & 0.01535 & 0.02462 & 0.01726 & 0.02653 & .02302 & 0.03229 & .03453 & 0.04380 & .04604 & 0.05531 \\
\hline
\end{tabular}




\begin{tabular}{|c|c|c|c|c|c|c|c|c|c|c|c|c|c|}
\hline 40 & 204600 & 0.01153 & 0.02080 & 0.01537 & 0.02464 & 0.01729 & 0.02656 & 0.02305 & 0.03232 & 0.03458 & 0.04385 & 0.04611 & 0.05538 \\
\hline 45 & 204300 & 0.01154 & 0.02081 & 0.01539 & .02466 & 01732 & .02658 & 02309 & 0.03236 & 0.03463 & 0.04390 & 0.04618 & 0.05544 \\
\hline 50 & 204000 & 0.01156 & .02083 & 0.01541 & .02468 & 0.01734 & .02661 & 0.02312 & 0.03239 & 0.03468 & 0.04395 & 0.04624 & 0.05551 \\
\hline 55 & 203700 & 01158 & 0.02085 & 0.01544 & .02471 & 0.01737 & 0.02664 & 0.02316 & 0.03242 & 0.03473 & 0.04400 & 0.04631 & 0.05558 \\
\hline 60 & 203400 & 01159 & .02086 & 0.01546 & .02473 & 0.01739 & .02666 & 0.02319 & 0.03246 & 0.03478 & 0.04405 & 0.04638 & 0.05565 \\
\hline 65 & 203100 & 01161 & .02088 & 0.01548 & .02475 & 0.01742 & 0.02669 & 0.02322 & 0.03249 & 0.03484 & 0.04410 & 0.04645 & 0.05572 \\
\hline 70 & 202800 & 01163 & 0.02090 & 0.01551 & .02477 & .01744 & 02671 & 0.02326 & 03253 & 0.03489 & 0.04416 & 0.04652 & 0.05579 \\
\hline 75 & 202500 & .01165 & 0.02091 & 0.01553 & 0.02480 & 0.01747 & 0.02674 & 0.02329 & 0.03256 & 0.03494 & 0.04421 & 0.04659 & 0.05585 \\
\hline 80 & 202200 & 01166 & 0.02093 & 0.01555 & 0.02482 & 0.01750 & 0.02676 & 0.02333 & 0.03260 & 0.03499 & 0.04426 & 0.04665 & 0.05592 \\
\hline 85 & 201900 & 01168 & 0.02095 & 0.01557 & 0.02484 & 0.01752 & 0.02679 & 0.02336 & 0.03263 & 0.03504 & 0.04431 & 0.04672 & 0.05599 \\
\hline 90 & 201600 & 0.01170 & 0.02097 & 0.01560 & 0.02487 & 0.01755 & 0.02682 & 0.02340 & 0.03267 & 0.03510 & 0.04436 & 0.04679 & 0.05606 \\
\hline 95 & 201300 & 01172 & 0.02098 & 0.01562 & 0.02489 & 0.01757 & 0.02684 & 0.02343 & 0.03270 & 0.03515 & 0.04442 & 0.04686 & 0.05613 \\
\hline 100 & 201000 & D1173 & 0.02100 & 0.01564 & 0.02491 & 0.01760 & 0.02687 & 0.02347 & 0.03274 & 0.03520 & 0.04447 & 04693 & .05620 \\
\hline 105 & 200700 & 01175 & 0.02102 & 0.01567 & 0.02494 & 0.01763 & 02689 & 0.02350 & D3277 & 0.03525 & 0.04452 & .04700 & 0.05627 \\
\hline 110 & 200400 & 01177 & 0.02104 & 0.01569 & 0.02496 & 0.01765 & 0.02692 & 0.02354 & 0.03281 & 0.03531 & 0.04457 & 0.04707 & 0.05634 \\
\hline 115 & 200100 & 01179 & 0.02105 & 0.01571 & 0.02498 & 0.01768 & 0.02695 & 0.02357 & 0.03284 & 0.03536 & 0.04463 & 0.04714 & 0.05641 \\
\hline 120 & 199800 & 01180 & 0.02107 & 0.01574 & 0.02501 & 0.01771 & 0.02697 & 361 & 0.03288 & 3541 & 0.04468 & 4722 & 0.05648 \\
\hline 125 & 199500 & 01182 & 0.02109 & 0.01576 & .02503 & 0.01773 & 0.02700 & 364 & 0.03291 & 546 & 0.04473 & 4729 & 0.05655 \\
\hline 130 & 199200 & 01184 & 0.02111 & 0.01579 & 0.02505 & 0.01776 & 0.02703 & 0.02368 & 0.03295 & 0.03552 & 0.04479 & 0.04736 & 0.05663 \\
\hline 135 & 198900 & 01186 & 0.02113 & 0.01581 & 0.02508 & 0.01779 & 0.02705 & 0.02371 & 0.03298 & 0.03557 & 0.04484 & 0.04743 & 0.05670 \\
\hline 140 & 198600 & 01188 & 0.02114 & 0.01583 & 0.02510 & 0.01781 & .02708 & 0.02375 & .03302 & 0.03563 & 0.04489 & .04750 & 0.05677 \\
\hline 145 & 198300 & D1189 & 0.02116 & 0.01586 & 0.02513 & 0.01784 & 2711 & 79 & 0.03305 & 68 & 0.04495 & 4757 & 0.05684 \\
\hline 150 & 198000 & 01191 & 0.02118 & 0.01588 & 0.02515 & 0.01787 & 0.02714 & 0.02382 & 0.03309 & 3573 & 0.04500 & 4764 & 0.05691 \\
\hline 155 & 197700 & 01193 & 0.02120 & 0.01591 & 0.02517 & 0.01789 & 0.02716 & 0.02386 & 0.03313 & 0.03579 & 0.04506 & .04772 & 0.05699 \\
\hline 160 & 197400 & 01195 & 0.02122 & 0.01593 & 0.02520 & 0.01792 & 0.02719 & 0.02389 & 0.03316 & 0.03584 & 0.04511 & 0.04779 & 0.05706 \\
\hline 165 & 197100 & D1197 & 0.02123 & 0.01595 & & 0.01795 & & & & 0.03590 & & 786 & 713 \\
\hline 170 & 196800 & 01198 & 0.02125 & 0.01598 & & 0.01798 & & & & & & 793 & 720 \\
\hline 175 & 196500 & 1200 & 0.02127 & 0.01600 & 0.02527 & 0.01800 & 2727 & 400 & 0.03327 & 01 & 0.04527 & 4801 & 0.05728 \\
\hline 180 & 196200 & 01202 & 0.02129 & 0.01603 & 0.02530 & 0.01803 & 0.02730 & 0.02404 & 0.03331 & 0.03606 & 0.04533 & 0.04808 & 0.05735 \\
\hline 185 & 195900 & 01204 & 0.02131 & 0.01605 & 0.02532 & 0.01806 & 0.02733 & 0.02408 & 0.03335 & 0.03612 & 0.04538 & .04816 & 0.05742 \\
\hline 190 & 195600 & 01206 & 0.02133 & 0.01608 & 0.02534 & 0.01809 & .02735 & 0.02411 & 0.03338 & 0.03617 & 0.04544 & 0.04823 & 0.05750 \\
\hline 195 & 195300 & 0.01208 & 0.02 & 0.01610 & & & & & & & & 4830 & 5757 \\
\hline 200 & 195000 & 1209 & 136 & 0.01613 & & 0.01 & & & & & & & 0.05765 \\
\hline 205 & 194700 & D1211 & 0.02138 & 0.01615 & 0.02542 & 0.01817 & 0.02744 & 2423 & 0.03349 & 3634 & 0.04561 & 04845 & 0.05772 \\
\hline 210 & 194400 & 01213 & 0.02140 & 0.01618 & 0.02544 & 0.01820 & 0.02747 & 0.02426 & 0.03353 & 0.03640 & 0.04566 & 0.04853 & 0.05780 \\
\hline 215 & 194100 & 01215 & 0.02142 & 0.01620 & 0.02547 & 0.01823 & 0.02749 & 0.02430 & 0.03357 & 0.03645 & 0.04572 & 0.04860 & 0.05787 \\
\hline 220 & 193800 & D1217 & 0.02144 & 0.01623 & 0.02549 & 0.01825 & 02752 & 34 & 361 & 551 & 578 & 868 & 5795 \\
\hline 225 & 193500 & D1219 & 0.02146 & 0.01625 & 0.02552 & 0.01828 & 55 & 38 & & & 83 & 375 & 802 \\
\hline 230 & & 1221 & 48 & 0.01628 & & 0.0 & & & & & 89 & 383 & 810 \\
\hline 235 & 192900 & 1223 & 0.02149 & 0.01630 & 0.02557 & 0.01834 & 0.02761 & 0.02445 & 03372 & 0.03668 & 0.04595 & 04890 & 0.05817 \\
\hline 240 & 192600 & 01225 & 0.02151 & 0.01633 & 0.02560 & 0.01837 & 0.02764 & 0.02449 & 0.03376 & 0.03674 & 0.04600 & 0.04898 & 0.05825 \\
\hline 245 & 192300 & 01226 & 0.02153 & 0.01635 & 0.02562 & 0.01840 & 0.02766 & 0.02453 & 0.03380 & 0.03679 & 0.04606 & 04906 & 0.05833 \\
\hline 250 & 192000 & D1228 & 0.02155 & 0.01638 & 0.02565 & 0.01842 & 0.02769 & 0.02457 & 384 & 685 & 0.04612 & 04913 & 0.05840 \\
\hline 255 & 191700 & 01230 & 0.02157 & 0.01640 & 0.02567 & 0.01845 & 02772 & & 387 & & 618 & 0.04921 & 0.05848 \\
\hline 260 & 191400 & 1232 & 0.02159 & 0.01643 & 0.02570 & 0.01848 & 775 & 0.02464 & 0.03391 & 0.03697 & 0.04623 & 0.04929 & 0.05856 \\
\hline 265 & 191100 & 1234 & 0.02161 & 0.01645 & 0.02572 & 0.01851 & 02778 & 02468 & 3395 & 03702 & 04629 & 04936 & 0.05863 \\
\hline 270 & 190800 & 1236 & 0.02163 & 0.01648 & 0.02575 & 0.01854 & 0.02781 & 0.02472 & 03399 & 0.03708 & 0.04635 & 0.04944 & 0.05871 \\
\hline 275 & 190500 & 0.01238 & 0.02165 & 0.01651 & 0.02578 & 0.01857 & 0.02784 & 0.02476 & 0.03403 & 0.03714 & 0.04641 & 0.04952 & 0.05879 \\
\hline 280 & 190200 & 01240 & 0.02167 & 0.01653 & 0.02580 & 0.01860 & 0.02787 & 0.02480 & 0.03407 & 0.03720 & 0.04647 & 0.04960 & 0.05887 \\
\hline 285 & 189900 & D1242 & 0.02169 & 0.01656 & 0.02583 & 0.01863 & 2790 & 0.02484 & 3411 & 0.03726 & 0.04653 & 0.04968 & 0.05895 \\
\hline 29 & 600 & 1244 & 2171 & 0.01659 & 85 & 56 & & 188 & 415 & 3732 & 658 & 4976 & 0.05902 \\
\hline 295 & 189300 & 1246 & 0.02173 & 0.01661 & 0.02588 & 0.01869 & 0.02796 & 0.02492 & 419 & 0.03738 & 0.04664 & 0.04983 & 0.05910 \\
\hline 300 & 189000 & 0.01248 & 0.02175 & 0.01664 & 0.02591 & 0.01872 & 0.02799 & 0.02496 & 0.03423 & 0.03743 & 0.04670 & 0.04991 & 0.05918 \\
\hline
\end{tabular}


Machine compliance: $0.087124 \mathrm{~mm} / \mathrm{kN}$

\begin{tabular}{|c|c|c|c|}
\hline \multirow{2}{*}{\multicolumn{2}{|c|}{ Specimen type: }} & \multirow{2}{*}{\multicolumn{2}{|c|}{ KLST }} \\
\hline & & & \\
\hline \multicolumn{2}{|c|}{ Thickness B $(\mathrm{mm})=$} & \multicolumn{2}{|c|}{3} \\
\hline \multicolumn{2}{|c|}{ Span $\mathrm{S}(\mathrm{mm})=$} & \multicolumn{2}{|c|}{22} \\
\hline \multicolumn{2}{|c|}{ Width $\mathrm{W}(\mathrm{mm})=$} & \multicolumn{2}{|c|}{4} \\
\hline \multicolumn{2}{|c|}{ Notch depth a $(\mathrm{mm})=$} & \multicolumn{2}{|c|}{1} \\
\hline \multirow{3}{*}{\multicolumn{2}{|c|}{$\begin{array}{r}a / W= \\
f(a / W)=\end{array}$}} & \multicolumn{2}{|c|}{0.25} \\
\hline & & \multicolumn{2}{|c|}{0.915246094} \\
\hline & & \multicolumn{2}{|c|}{ KLST } \\
\hline$T$ & $\bar{E}$ & $\mathrm{C}_{\mathrm{s}}$ & $C_{\text {exp }}$ \\
\hline$\left({ }^{\circ} \mathrm{C}\right)$ & $\left(\mathrm{N} / \mathrm{mm}^{2}\right)$ & \multicolumn{2}{|c|}{$(\mathrm{mm} / \mathrm{kN})$} \\
\hline-180 & 217800 & 0.07533 & 0.16245 \\
\hline-175 & 217500 & 0.07543 & 0.16256 \\
\hline-170 & 217200 & 0.07554 & 0.16266 \\
\hline-165 & 216900 & 0.07564 & 0.16277 \\
\hline-160 & 216600 & 0.07575 & 0.16287 \\
\hline-155 & 216300 & 0.07585 & 0.16298 \\
\hline-150 & 216000 & 0.07596 & 0.16308 \\
\hline-145 & 215700 & 0.07606 & 0.16319 \\
\hline-140 & 215400 & 0.07617 & 0.16329 \\
\hline-135 & 215100 & 0.07627 & 0.16340 \\
\hline-130 & 214800 & 0.07638 & 0.16351 \\
\hline-125 & 214500 & 0.07649 & 0.16361 \\
\hline-120 & 214200 & 0.07659 & 0.16372 \\
\hline-115 & 213900 & 0.07670 & 0.16383 \\
\hline-110 & 213600 & 0.07681 & 0.16393 \\
\hline-105 & 213300 & 0.07692 & 0.16404 \\
\hline-100 & 213000 & 0.07703 & 0.16415 \\
\hline-95 & 212700 & 0.07714 & 0.16426 \\
\hline-90 & 212400 & 0.07724 & 0.16437 \\
\hline-85 & 212100 & 0.07735 & 0.16448 \\
\hline-80 & 211800 & 0.07746 & 0.16459 \\
\hline-75 & 211500 & 0.07757 & 0.16470 \\
\hline-70 & 211200 & 0.07768 & 0.16481 \\
\hline-65 & 210900 & 0.07779 & 0.16492 \\
\hline-60 & 210600 & 0.07790 & 0.16503 \\
\hline-55 & 210300 & 0.07802 & 0.16514 \\
\hline-50 & 210000 & 0.07813 & 0.16525 \\
\hline-45 & 209700 & 0.07824 & 0.16536 \\
\hline-40 & 209400 & 0.07835 & 0.16547 \\
\hline-35 & 209100 & 0.07846 & 0.16559 \\
\hline-30 & 208800 & 0.07858 & 0.16570 \\
\hline-25 & 208500 & 0.07869 & 0.16581 \\
\hline-20 & 208200 & 0.07880 & 0.16593 \\
\hline-15 & 207900 & 0.07892 & 0.16604 \\
\hline
\end{tabular}




\begin{tabular}{|c|c|c|c|}
\hline-10 & 207600 & 0.07903 & 0.16615 \\
\hline-5 & 207300 & 0.07914 & 0.16627 \\
\hline 0 & 207000 & 0.07926 & 0.16638 \\
\hline 5 & 206700 & 0.07937 & 0.16650 \\
\hline 10 & 206400 & 0.07949 & 0.16661 \\
\hline 15 & 206100 & 0.07961 & 0.16673 \\
\hline 20 & 205800 & 0.07972 & 0.16685 \\
\hline 21 & 205740 & 0.07974 & 0.16687 \\
\hline 22 & 205680 & 0.07977 & 0.16689 \\
\hline 23 & 205620 & 0.07979 & 0.16692 \\
\hline 24 & 205560 & 0.07981 & 0.16694 \\
\hline 25 & 205500 & 0.07984 & 0.16696 \\
\hline 30 & 205200 & 0.07995 & 0.16708 \\
\hline 35 & 204900 & 0.08007 & 0.16720 \\
\hline 40 & 204600 & 0.08019 & 0.16731 \\
\hline 45 & 204300 & 0.08031 & 0.16743 \\
\hline 50 & 204000 & 0.08042 & 0.16755 \\
\hline 55 & 203700 & 0.08054 & 0.16767 \\
\hline 60 & 203400 & 0.08066 & 0.16779 \\
\hline 65 & 203100 & 0.08078 & 0.16791 \\
\hline 70 & 202800 & 0.08090 & 0.16802 \\
\hline 75 & 202500 & 0.08102 & 0.16814 \\
\hline 80 & 202200 & 0.08114 & 0.16826 \\
\hline 85 & 201900 & 0.08126 & 0.16839 \\
\hline 90 & 201600 & 0.08138 & 0.16851 \\
\hline 95 & 201300 & 0.08150 & 0.16863 \\
\hline 100 & 201000 & 0.08163 & 0.16875 \\
\hline 105 & 200700 & 0.08175 & 0.16887 \\
\hline 110 & 200400 & 0.08187 & 0.16899 \\
\hline 115 & 200100 & 0.08199 & 0.16912 \\
\hline 120 & 199800 & 0.08212 & 0.16924 \\
\hline 125 & 199500 & 0.08224 & 0.16936 \\
\hline 130 & 199200 & 0.08236 & 0.16949 \\
\hline 135 & 198900 & 0.08249 & 0.16961 \\
\hline 140 & 198600 & 0.08261 & 0.16974 \\
\hline 145 & 198300 & 0.08274 & 0.16986 \\
\hline 150 & 198000 & 0.08286 & 0.16999 \\
\hline 155 & 197700 & 0.08299 & 0.17011 \\
\hline 160 & 197400 & 0.08311 & 0.17024 \\
\hline 165 & 197100 & 0.08324 & 0.17036 \\
\hline 170 & 196800 & 0.08337 & 0.17049 \\
\hline 175 & 196500 & 0.08349 & 0.17062 \\
\hline 180 & 196200 & 0.08362 & 0.17075 \\
\hline 185 & 195900 & 0.08375 & 0.17087 \\
\hline 190 & 195600 & 0.08388 & 0.17100 \\
\hline 195 & 195300 & 0.08401 & 0.17113 \\
\hline 200 & 195000 & 0.08414 & 0.17126 \\
\hline
\end{tabular}

Experimental compliance values for NIST Charpy machines.xlsx - TT-KLST 


\begin{tabular}{|l|l|ll|}
205 & 194700 & 0.08427 & $\mathbf{0 . 1 7 1 3 9}$ \\
210 & 194400 & 0.08440 & $\mathbf{0 . 1 7 1 5 2}$ \\
215 & 194100 & 0.08453 & $\mathbf{0 . 1 7 1 6 5}$ \\
220 & 193800 & 0.08466 & $\mathbf{0 . 1 7 1 7 8}$ \\
225 & 193500 & 0.08479 & $\mathbf{0 . 1 7 1 9 1}$ \\
230 & 193200 & 0.08492 & $\mathbf{0 . 1 7 2 0 4}$ \\
235 & 192900 & 0.08505 & $\mathbf{0 . 1 7 2 1 8}$ \\
240 & 192600 & 0.08519 & $\mathbf{0 . 1 7 2 3 1}$ \\
245 & 192300 & 0.08532 & $\mathbf{0 . 1 7 2 4 4}$ \\
250 & 192000 & 0.08545 & $\mathbf{0 . 1 7 2 5 8}$ \\
255 & 191700 & 0.08558 & $\mathbf{0 . 1 7 2 7 1}$ \\
260 & 191400 & 0.08572 & $\mathbf{0 . 1 7 2 8 4}$ \\
265 & 191100 & 0.08585 & $\mathbf{0 . 1 7 2 9 8}$ \\
270 & 190800 & 0.08599 & $\mathbf{0 . 1 7 3 1 1}$ \\
275 & 190500 & 0.08612 & $\mathbf{0 . 1 7 3 2 5}$ \\
280 & 190200 & 0.08626 & $\mathbf{0 . 1 7 3 3 8}$ \\
285 & 189900 & 0.08640 & $\mathbf{0 . 1 7 3 5 2}$ \\
290 & 189600 & 0.08653 & $\mathbf{0 . 1 7 3 6 6}$ \\
295 & 189300 & 0.08667 & $\mathbf{0 . 1 7 3 7 9}$ \\
300 & 189000 & 0.08681 & $\mathbf{0 . 1 7 3 9 3}$ \\
\hline
\end{tabular}


Machine compliance: $0.026963 \mathrm{~mm} / \mathrm{kN}$

\begin{tabular}{|c|c|c|c|}
\hline \multirow{2}{*}{\multicolumn{2}{|c|}{ Specimen type: }} & \multirow{2}{*}{\multicolumn{2}{|c|}{ RHS }} \\
\hline & & & \\
\hline \multicolumn{2}{|c|}{ Thickness $B(\mathrm{~mm})=$} & \multicolumn{2}{|c|}{4.83} \\
\hline \multicolumn{2}{|c|}{ Span $\mathrm{S}(\mathrm{mm})=$} & \multicolumn{2}{|c|}{19.3} \\
\hline \multicolumn{2}{|c|}{ Width $\mathrm{W}(\mathrm{mm})=$} & \multicolumn{2}{|c|}{4.83} \\
\hline \multicolumn{2}{|c|}{ Notch depth a $(\mathrm{mm})=$} & \multicolumn{2}{|c|}{0.97} \\
\hline \multirow{3}{*}{\multicolumn{2}{|c|}{$\begin{array}{r}a / w= \\
f(a / W)=\end{array}$}} & \multicolumn{2}{|c|}{0.200828157} \\
\hline & & \multicolumn{2}{|c|}{0.942808116} \\
\hline & & \multicolumn{2}{|c|}{ KLST } \\
\hline$T$ & $\bar{E}$ & $\mathrm{C}_{\mathrm{s}}$ & $C_{\text {exp }}$ \\
\hline$\left({ }^{\circ} \mathrm{C}\right)$ & $\left(\mathrm{N} / \mathrm{mm}^{2}\right)$ & \multicolumn{2}{|c|}{$(\mathrm{mm} / \mathrm{kN})$} \\
\hline-180 & 217800 & 0.02241 & 0.04937 \\
\hline-175 & 217500 & 0.02244 & 0.04940 \\
\hline-170 & 217200 & 0.02247 & 0.04943 \\
\hline-165 & 216900 & 0.02250 & 0.04946 \\
\hline-160 & 216600 & 0.02253 & 0.04949 \\
\hline-155 & 216300 & 0.02256 & 0.04952 \\
\hline-150 & 216000 & 0.02259 & 0.04956 \\
\hline-145 & 215700 & 0.02262 & 0.04959 \\
\hline-140 & 215400 & 0.02266 & 0.04962 \\
\hline-135 & 215100 & 0.02269 & 0.04965 \\
\hline-130 & 214800 & 0.02272 & 0.04968 \\
\hline-125 & 214500 & 0.02275 & 0.04971 \\
\hline-120 & 214200 & 0.02278 & 0.04974 \\
\hline-115 & 213900 & 0.02281 & 0.04978 \\
\hline-110 & 213600 & 0.02285 & 0.04981 \\
\hline-105 & 213300 & 0.02288 & 0.04984 \\
\hline-100 & 213000 & 0.02291 & 0.04987 \\
\hline-95 & 212700 & 0.02294 & 0.04991 \\
\hline-90 & 212400 & 0.02298 & 0.04994 \\
\hline-85 & 212100 & 0.02301 & 0.04997 \\
\hline-80 & 211800 & 0.02304 & 0.05000 \\
\hline-75 & 211500 & 0.02307 & 0.05004 \\
\hline-70 & 211200 & 0.02311 & 0.05007 \\
\hline-65 & 210900 & 0.02314 & 0.05010 \\
\hline-60 & 210600 & 0.02317 & 0.05013 \\
\hline-55 & 210300 & 0.02320 & 0.05017 \\
\hline-50 & 210000 & 0.02324 & 0.05020 \\
\hline-45 & 209700 & 0.02327 & 0.05023 \\
\hline-40 & 209400 & 0.02330 & 0.05027 \\
\hline-35 & 209100 & 0.02334 & 0.05030 \\
\hline-30 & 208800 & 0.02337 & 0.05033 \\
\hline-25 & 208500 & 0.02341 & 0.05037 \\
\hline-20 & 208200 & 0.02344 & 0.05040 \\
\hline-15 & 207900 & 0.02347 & 0.05044 \\
\hline
\end{tabular}

Experimental compliance values for NIST Charpy machines.xIsx - TT-RHS 


\begin{tabular}{|c|c|c|c|}
\hline-10 & 207600 & 0.02351 & 0.05047 \\
\hline-5 & 207300 & 0.02354 & 0.05050 \\
\hline 0 & 207000 & 0.02357 & 0.05054 \\
\hline 5 & 206700 & 0.02361 & 0.05057 \\
\hline 10 & 206400 & 0.02364 & 0.05061 \\
\hline 15 & 206100 & 0.02368 & 0.05064 \\
\hline 20 & 205800 & 0.02371 & 0.05067 \\
\hline 21 & 205740 & 0.02372 & 0.05068 \\
\hline 22 & 205680 & 0.02373 & 0.05069 \\
\hline 23 & 205620 & 0.02373 & 0.05070 \\
\hline 24 & 205560 & 0.02374 & 0.05070 \\
\hline 25 & 205500 & 0.02375 & 0.05071 \\
\hline 30 & 205200 & 0.02378 & 0.05074 \\
\hline 35 & 204900 & 0.02382 & 0.05078 \\
\hline 40 & 204600 & 0.02385 & 0.05081 \\
\hline 45 & 204300 & 0.02389 & 0.05085 \\
\hline 50 & 204000 & 0.02392 & 0.05088 \\
\hline 55 & 203700 & 0.02396 & 0.05092 \\
\hline 60 & 203400 & 0.02399 & 0.05095 \\
\hline 65 & 203100 & 0.02403 & 0.05099 \\
\hline 70 & 202800 & 0.02406 & 0.05103 \\
\hline 75 & 202500 & 0.02410 & 0.05106 \\
\hline 80 & 202200 & 0.02413 & 0.05110 \\
\hline 85 & 201900 & 0.02417 & 0.05113 \\
\hline 90 & 201600 & 0.02421 & 0.05117 \\
\hline 95 & 201300 & 0.02424 & 0.05120 \\
\hline 100 & 201000 & 0.02428 & 0.05124 \\
\hline 105 & 200700 & 0.02431 & 0.05128 \\
\hline 110 & 200400 & 0.02435 & 0.05131 \\
\hline 115 & 200100 & 0.02439 & 0.05135 \\
\hline 120 & 199800 & 0.02442 & 0.05139 \\
\hline 125 & 199500 & 0.02446 & 0.05142 \\
\hline 130 & 199200 & 0.02450 & 0.05146 \\
\hline 135 & 198900 & 0.02453 & 0.05150 \\
\hline 140 & 198600 & 0.02457 & 0.05153 \\
\hline 145 & 198300 & 0.02461 & 0.05157 \\
\hline 150 & 198000 & 0.02465 & 0.05161 \\
\hline 155 & 197700 & 0.02468 & 0.05165 \\
\hline 160 & 197400 & 0.02472 & 0.05168 \\
\hline 165 & 197100 & 0.02476 & 0.05172 \\
\hline 170 & 196800 & 0.02480 & 0.05176 \\
\hline 175 & 196500 & 0.02483 & 0.05180 \\
\hline 180 & 196200 & 0.02487 & 0.05183 \\
\hline 185 & 195900 & 0.02491 & 0.05187 \\
\hline 190 & 195600 & 0.02495 & 0.05191 \\
\hline 195 & 195300 & 0.02499 & 0.05195 \\
\hline 200 & 195000 & 0.02503 & 0.05199 \\
\hline
\end{tabular}

Experimental compliance values for NIST Charpy machines.xlsx - TT-RHS 


\begin{tabular}{|l|l|ll|}
205 & 194700 & 0.02506 & $\mathbf{0 . 0 5 2 0 3}$ \\
210 & 194400 & 0.02510 & $\mathbf{0 . 0 5 2 0 7}$ \\
215 & 194100 & 0.02514 & $\mathbf{0 . 0 5 2 1 0}$ \\
220 & 193800 & 0.02518 & $\mathbf{0 . 0 5 2 1 4}$ \\
225 & 193500 & 0.02522 & $\mathbf{0 . 0 5 2 1 8}$ \\
230 & 193200 & 0.02526 & $\mathbf{0 . 0 5 2 2 2}$ \\
235 & 192900 & 0.02530 & $\mathbf{0 . 0 5 2 2 6}$ \\
240 & 192600 & 0.02534 & $\mathbf{0 . 0 5 2 3 0}$ \\
245 & 192300 & 0.02538 & $\mathbf{0 . 0 5 2 3 4}$ \\
250 & 192000 & 0.02542 & $\mathbf{0 . 0 5 2 3 8}$ \\
255 & 191700 & 0.02546 & $\mathbf{0 . 0 5 2 4 2}$ \\
260 & 191400 & 0.02550 & $\mathbf{0 . 0 5 2 4 6}$ \\
265 & 191100 & 0.02554 & $\mathbf{0 . 0 5 2 5 0}$ \\
270 & 190800 & 0.02558 & $\mathbf{0 . 0 5 2 5 4}$ \\
275 & 190500 & 0.02562 & $\mathbf{0 . 0 5 2 5 8}$ \\
280 & 190200 & 0.02566 & $\mathbf{0 . 0 5 2 6 2}$ \\
285 & 189900 & 0.02570 & $\mathbf{0 . 0 5 2 6 6}$ \\
290 & 189600 & 0.02574 & $\mathbf{0 . 0 5 2 7 0}$ \\
295 & 189300 & 0.02578 & $\mathbf{0 . 0 5 2 7 4}$ \\
300 & 189000 & 0.02582 & $\mathbf{0 . 0 5 2 7 8}$ \\
\hline
\end{tabular}

